\title{
Exposures of Aquatic Organisms to the Organophosphorus Insecticide, Chlorpyrifos Resulting from Use in the United States
}

\author{
W. Martin Williams, Jeffrey M. Giddings, John Purdy, \\ Keith R. Solomon, and John P. Giesy
}

\section{Introduction}

Chlorpyrifos ( $O, O$-diethyl $O$-(3,5,6-trichloro-2-pyridinyl) phosphorothioate) is an organophosphorus insecticide that has been detected in surface waters of the United States (CDPR 2012a; Martin et al. 2011; NCWQR 2012; WDOE 2012). The potential for chlorpyrifos (CPY) to occur in surface water is governed by complex interactions of factors related to application, agronomic practices, climatological conditions during and after application, soil pedology and chemistry, hydrologic responses of drainage systems, and its physicochemical properties that affect mobility and persistence under those environmental settings. These conditions vary among patterns of use such as the crop to which it is applied within the different regions of the country that have different soil types and climates. CPY use and registrations have changed over time as a result of market forces and product stewardship, including the ban of retail use and

The online version of this chapter (doi:10.1007/978-3-319-03865-0_4) contains supplementary material, which is available to authorized users.

W.M. Williams $(\bowtie)$

Waterborne Environmental Inc., Leesburg, VA, USA

e mail:williamsm@waterborne-env.com

J.M. Giddings

Compliance Services International, Rochester, MA, USA

J. Purdy

Abacus Consulting, Campbellville, ON, Canada

K.R. Solomon

Centre for Toxicology, School of Environmental Sciences, University of Guelph,

Guelph, ON, Canada

J.P. Giesy

Department of Veterinary Biomedical Sciences and Toxicology Centre,

University of Saskatchewan, 44 Campus Dr., Saskatoon, SK S7N 5B3, Canada 


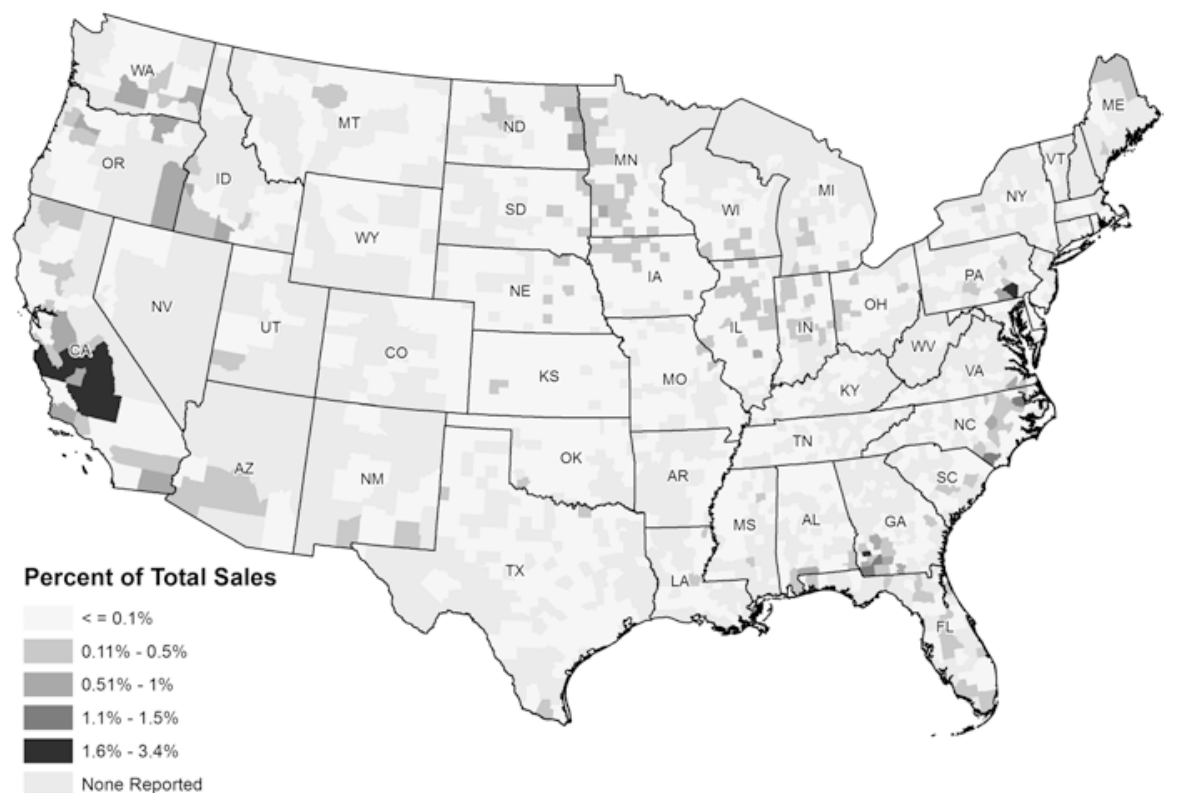

Fig. 1 Geographical distribution of chlorpyrifos use in the United States from 2010 to 2011. Derived from confidential sales data (from Dow AgroSciences, 2012; see SI for a color version of this Figure)

the implementation of other label changes for environmental stewardship that were implemented in 2001. The objective of this study was to characterize likely exposures of aquatic organisms to CPY in the U.S. by evaluating patterns of use, environmental chemistry, available monitoring data, and via simulation modeling. The results of the data analyses and simulation modeling are a key component of the CPY risk assessment described in the companion paper (Giddings et al. 2014).

\subsection{Distribution of Use of Chlorpyrifos}

CPY is one of the insecticides most widely used throughout the world to limit insect and mite damage to a number of important crops, including soybeans, corn, tree nuts, alfalfa, wheat, citrus, peanuts, and vegetables, among others (Solomon et al. 2014). Regions in the U.S. with the largest use of CPY in 2010-2011, expressed as percent of insecticide, include the Central Valley of California; the Snake River basin in Oregon and southwestern Idaho; parts of Minnesota, Iowa, Wisconsin, Illinois, Indiana, Ohio and Michigan in the central and eastern corn belt; and areas in Georgia and North Carolina along the Atlantic and Gulf coastal plain (Fig. 1). Soybeans, corn, tree nuts (almonds, pecans and walnuts), apples, alfalfa, wheat, and sugar beets accounted for approximately 80\% of the use of CPY in 2007 (Fig. 2).

CPY is available as a granular product for soil treatment, or several flowable formulations (all formulations that are sprayed) that can be applied to foliage, soil, 


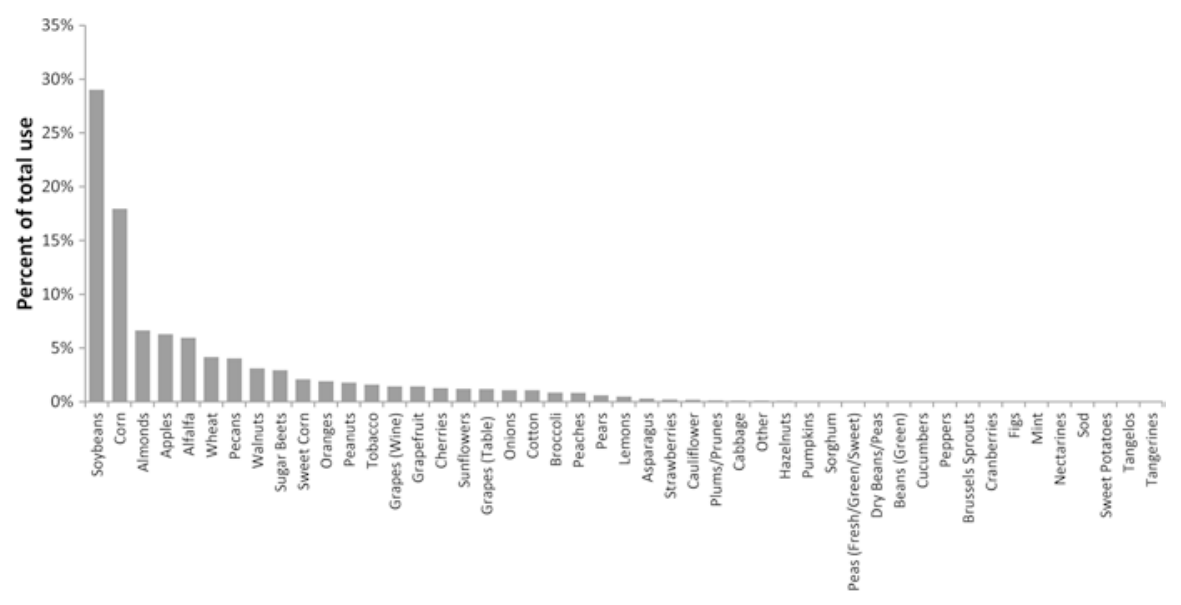

Fig. 2 Use of chlorpyrifos by crop (2007) (data from Gomez 2009)

or dormant trees (Solomon et al. 2014). Application can occur pre-plant, at-plant, post-plant or during the dormant season using aerial equipment, chemigation, ground boom or air-blast sprayers, tractor-drawn spreaders, or hand-held equipment.

\subsection{Environmental Fate Properties}

CPY has short to moderate persistence in the environment as a result of several pathways of dissipation, including volatilization, photolysis, abiotic hydrolysis and microbial degradation that can occur concurrently. Dissipation by volatilization from foliage, as controlled by the physical and chemical properties of CPY (Tables 1 and 2) is the dominant process during the first $12 \mathrm{~h}$ after application, but decreases as the formulation adsorbs to foliage or soil (Mackay et al. 2014). During the days following application, CPY strongly adsorbs to soil and penetrates the soil profile to become less available for volatilization, and consequently other degradation processes become important. The magnitude of CPY adsorption varies substantially between different soils, with a spread of two orders of magnitude in calculated $\mathrm{Kd}$ coefficients (SI Table A4).

Key factors affecting degradation of CPY in soil have been reviewed previously (Racke 1993) and these factors have been substantiated by additional recent research cited herein. CPY can be degraded by UV radiation, dechlorination, hydrolysis, and microbial processes. However, hydrolysis of CPY is the primary mechanism and results in formation of 3,5,6-trichloropyridinol (TCP). This step can be either abiotic or biotic, and the rate is 1.7- to 2-fold faster in biologically active soils. The rate of abiotic hydrolysis is $\mathrm{pH}$-dependent and occurs more rapidly under alkaline conditions. It is also faster in the presence of catalysts such as certain types of clay (Racke 1993). Degradation of TCP is dependent on biological activity, and leads to 
Table 1 Key physicochemical properties of chlorpyrifos

\begin{tabular}{lll}
\hline Parameter & Value & Source \\
\hline Chemical name & $\begin{array}{c}\text { O,O-diethyl } \\
\text { o-(3,5,6-trichloro-2-pyridyl } \\
\text { phosphorothioate }\end{array}$ & USEPA (2011) \\
$\begin{array}{l}\text { Chemical Abstracts Service (CAS) } \\
\quad \text { Registry Number }\end{array}$ & $\begin{array}{l}2921-88-2 \\
\text { Empirical formula }\end{array}$ & USEPA (2011) \\
Molecular mass & $\mathrm{C} 20 \mathrm{H} 17 \mathrm{~F} 5 \mathrm{~N} 2 \mathrm{O} 2$ & USEPA (2011) \\
Vapor pressure $\left(25^{\circ} \mathrm{C}\right)$ & $350.6 \mathrm{~g} / \mathrm{mol}$ & Mackay et al. (2014) \\
Water solubility $\left(20^{\circ} \mathrm{C}\right)$ & $1.73 \times 10^{-5}$ torr & Mackay et al. (2014) \\
Henry's law constant & $0.73 \mathrm{mg} / \mathrm{L}$ & Mackay et al. (2014) \\
Log K $\mathrm{K}_{\mathrm{ow}}$ & $1.10 \times 10^{-5} \mathrm{~atm}-\mathrm{m}^{3} / \mathrm{mol}$ & Mackay et al. (2014) \\
\hline
\end{tabular}

Table 2 Key environmental fate properties of chlorpyrifos

\begin{tabular}{|c|c|c|}
\hline Parameter & Value & Source \\
\hline \multirow[t]{4}{*}{ Hydrolysis $\left(\mathrm{t}^{1} / 2\right)$} & $\mathrm{pH} 5: 73 \mathrm{~d}$ & USEPA (2011) \\
\hline & $\mathrm{pH} 7: 72 \mathrm{~d}$ & \\
\hline & $\mathrm{pH} 7: 81 \mathrm{~d}$ & \\
\hline & $\mathrm{pH} 9: 16 \mathrm{~d}$ & \\
\hline Aqueous photolysis $\left(\mathrm{t}^{1} / 2\right)$ & $29.6 \mathrm{~d}$ & USEPA (2011) \\
\hline Aerobic soil metabolism $\left(\mathrm{t}^{1 / 2}\right)^{\mathrm{a}}$ & $1.9-1576 \mathrm{~d}$ & See Table SI A1 \\
\hline Aerobic aquatic metabolism ( $\left.\mathrm{t}^{1 / 2}\right)$ & $22-51 \mathrm{~d}$ & See Table SI A5 \\
\hline Anaerobic soil metabolism $\left(t^{1 / 2}\right)$ & 15 and $58 \mathrm{~d}$ & USEPA (2011) \\
\hline Anaerobic aquatic metabolism $\left(\mathrm{t}^{1} / 2\right)$ & 39 and $51 \mathrm{~d}$ & USEPA (2011) \\
\hline Soil adsorption coefficient $\mathrm{K}_{\mathrm{OC}}$ & $973-31,000 \mathrm{~cm}^{3} \mathrm{~g}^{-1}$ & See Table SI A4 \\
\hline Terrestrial field dissipation $\left(t^{1} / 2\right)$ & $1.3-120 \mathrm{~d}$ & See Table SI A3 \\
\hline
\end{tabular}

$\mathrm{t}^{1} \mathrm{2} / 2=$ half-life

${ }^{a}$ All values $<335 \mathrm{~d}$ except one

formation of bound residues and reversible formation of 3,5,6-trichloro-2-methoxypyridinol (TMP). Under aerobic conditions, the major terminal degradation product of CPY is $\mathrm{CO}_{2}$. Since TCP and TMP are not considered to be residues of concern (USEPA 2011), they were not included in the model simulations presented below. Finally, while photolysis and oxidation are known to form the chlorpyrifos oxon (CPYO) in air and on foliar surfaces (Mackay et al. 2014), this route is either insignificant in soil or the oxon degrades as quickly as it is formed. CPYO has not been reported in radiotracer soil degradation studies in the laboratory or field. Concentrations of CPYO were not included in simulations because it has not been observed in soils.

Under standardized laboratory conditions, rates of degradation of CPY in soil, expressed as the half-life, have ranged from 1.3 to $1,575 \mathrm{~d}$ (all values except one are $<335 \mathrm{~d}$; see SI, Table A1). Although half-lives of 7-120 d are considered typical, this range narrows for medium textured soils across several states where reported half-lives range from 33 to $56 \mathrm{~d}$ (USEPA 1999). This variability in reported 
half-lives has been attributed to differences in soil organic carbon and moisture contents, prior CPY application rate, and microbial activity at the time of sampling, but no quantitative relationships have been reported (Racke 1993). Rates of degradation are inversely proportional to rates of application, possibly because concentrations in soil water reach the solubility limit of approximately $1 \mu \mathrm{g} \mathrm{CPY} \mathrm{L}^{-1}$. Generally, when applied as a granular product, CPY dissipation is slower than when applied as a liquid (Racke 1993). Dissipation under field conditions is also variable, with half-lives ranging from 1.3 to $120 \mathrm{~d}$ (SI, Table A2).

Results of laboratory aerobic degradation studies with CPY exhibit bi-phasic behavior in some soils. Initial rates of degradation are greater than overall rates by factors of 1.1 to 2.9 (Racke 1993). This behavior of CPY is not as apparent for some soils for which half-lives were calculated by use of simple, first-order kinetics (de Vette and Schoonmade 2001). Some half-lives reported in the literature (SI Table A1) have been derived by assuming first-order kinetics for degradation, which can overestimate the environmental persistence of CPY. This artifact is discussed in greater detail in the second paper of this series (Solomon et al. 2013).

CPY rapidly dissipates from plant surfaces, primarily from volatility and secondarily from photolysis, with most reported dissipation half-lives being on the order of several days (SI, Table A3). In a field study of CPY loss to air conducted in California, maximum fluxes via volatilization occurred in the first $8 \mathrm{~h}$ after application to recently cut alfalfa (Rotondaro and Havens 2012). The total loss of mass was calculated from fluxes determined by the Aerodynamic (AD) and Integrated Horizontal Flux (IHF) methodologies and ranged from 15.8 to $16.5 \%$ of the applied mass of CPY.

Based on reported water-sediment adsorption coefficients normalized to fraction of organic carbon in sediments $\left(\mathrm{K}_{\mathrm{OC}}\right)$ of $973-31,000 \mathrm{~cm}^{3} \mathrm{~g}^{-1}\left(\right.$ mean $8216 \mathrm{~cm}^{3} \mathrm{~g}^{-1}$, SI Appendix X, Table A4), CPY has moderate to high potential to adsorb to soil. Uptake by roots, translocation, and metabolism of CPY in plants are negligible and thus CPY is non-systemic, although metabolism of foliar-applied CPY does occur (Racke 1993).

In aquatic systems, abiotic degradation from aqueous hydrolysis of CPY has been reported to occur with half-lives of 73,72, and $16 \mathrm{~d}$ at $\mathrm{pH} 5,7$, and 9 , respectively at $25^{\circ} \mathrm{C}$ (Racke 1993). An aqueous hydrolysis half-life of $81 \mathrm{~d}$ at $\mathrm{pH} 7$ has been reported (USEPA 2011). Half-lives of 22-51 d have been reported from studies of aerobic metabolism in aquatic systems (SI Table A5, Kennard 1996; Reeves and Mackie 1993). A half-life of $29.6 \mathrm{~d}$ was observed in a aqueous photolysis study performed with CPY under sterile conditions at $\mathrm{pH} 7$ in phosphate-buffered solution under natural sunlight (Batzer et al. 1990).

Transport of CPY off-site following application has been extensively examined across a range of field conditions as affected by several factors: antecedent soil moisture, soil physical and chemical properties, soil erosion, plant canopy coverage, plant development stage, time intervals of 2-h to 7-d between application and rainfall events, and a range of rainfall events with return frequencies as little as 1-in833 yr (Cryer and Dixon-White 1995; McCall et al. 1984; Poletika and Robb 1994; Racke 1993). CPY mass in runoff ranged from 0.003 (McCall et al. 1984; Poletika and Robb 1994)) to 4.4\% (McCall et al. 1984; Poletika and Robb 1994) of applied 
mass. A study conducted in Iowa under record high rainfall conditions concluded that the majority of compound was transported attached to eroded sediment (Cryer and Dixon-White 1995). However, based on a combination of low erosion and availability of large amounts of residues on cotton foliage for wash-off during storms simulated soon after application of CPY, Poletika and Robb (1994) suggested that the majority of the CPY was transported in the dissolved phase of the runoff in Mississippi. Thus, both dissolved and adsorbed fractions need to be considered as transport pathways to surface water.

\section{Measurements of Chlorpyrifos in Aquatic Environments}

\subsection{Chlorpyrifos in Surface Water}

The most comprehensive dataset of pesticide concentrations has been compiled from the USGS National Water-Quality Assessment (NAWQA) Program and the National Stream Quality Accounting Network (NASQAN). These represent concentrations measured from 1992 to 2010 (Martin and Eberle 2009; Martin et al. 2011). Both NAWQA and NASQAN programs utilized similar methods to collect and process samples. Pesticide concentrations were determined by the USGS National Water Quality Laboratory (NWQL) by using gas chromatography/mass spectroscopy (GC/MS) in selective ion monitoring (SIM) mode. The USGS determined and applied a consistent minimum concentration as a bias correction to account for changes in recovery and limit of detection (LOD) ${ }^{1}$ during the sample collection period. A consistent method of rounding was applied to concentration values and quality control (QC) samples were removed from the data file before analysis. To allow for trend analysis, USGS added an attribute to the database to allow users to create a subset of the data that had no more than one sample per calendar week to avoid weighting the analysis toward periods of more frequent sampling.

The dataset reported by Martin et al. (2011) was characterized based on the percent of samples that contained detectable CPY. Characterization also included calculating 90th, 95th, and 99th centile concentrations and maximum concentrations for all samples. Data were categorized by year, Farm Resource Region ${ }^{2}$ (FRR; 9 total), and drainage basin land-use class (4 total). The basin land-use classes were agricultural ( $>50 \%$ agricultural and $\leq 5 \%$ urban), undeveloped ( $\leq 25 \%$ agricultural and $\leq 5 \%$ urban); urban ( $>25 \%$ urban and $\leq 25 \%$ agricultural); and mixed (all other combinations of urban, agricultural, and undeveloped land). To examine the effect of the 2001 ban on retail sales of CPY on measured concentrations, data for 19922001 and 2002-2010 were characterized separately.

\footnotetext{
${ }^{1}$ Level of detection (LOD) level of quantitation (LOQ) and method detection limit (MDL) are used as defined by MacDougall and Crummet (1980).

${ }^{2}$ A map and explanation of USDA's Economic Research Service (ERS) Farm Resource Regions is available at http://ageconsearch.umn.edu/bitstream/33625/1/ai000760.pdf.
} 


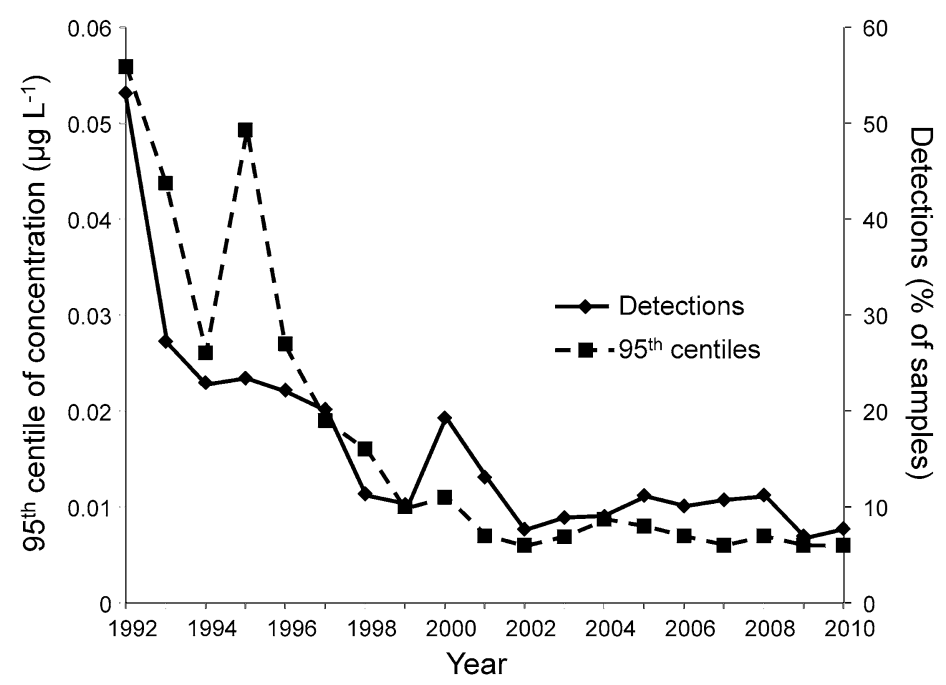

Fig. 3 Detections of chlorpyrifos and 95th centile concentrations in U.S. surface water, 19922010 (data from Martin et al. 2011)

Frequencies of detection and 95th centile concentrations decreased more than five-fold between 1992 and 2010 (Fig. 3). Detections in 1992-2001 ranged from 10.2 to $53.1 \%$, while $2002-2010$ detections ranged from 7.0 to $11.2 \%$. The 95 th centile concentrations ranged from 0.007 to $0.056 \mu \mathrm{g} \mathrm{L}^{-1}$ in $1992-2001$ and $0.006-$ $0.008 \mu \mathrm{g} \mathrm{L}^{-1}$ in 2002-2010. Localized intensive studies of CPY in surface waters also indicated the dramatic decrease in detection of CPY between 2001 and 2002, for example in Texas (Banks et al. 2005).

Farm Resource Regions (USDA-ERS 2000) with the greatest percent detections (Table 3) and the greatest 95th centile concentrations (Table 4) were the Fruitful Rim region and the Basin and Range region. Farms in the Basin and Range and Fruitful Rim FRRs include cattle, wheat, sorghum, fruit, vegetable, nursery and cotton farms in the western third of the U.S. and southern Texas, Florida, and southeastern Georgia and South Carolina (Martin et al. 2011).

The greatest frequency of detections (Table 3) and 95th centile concentrations (Table 4) occurred in undeveloped and agricultural land-use classes. The two landuse classes with the most urban land (urban and mixed) had the smallest frequency of detections and 95th centile concentrations, consistent with the cessation of CPY-based product sales for most homeowner uses in December 2001 (Johnson et al. 2011).

Databases in California and Washington were also examined to identify additional data on concentrations of CPY in surface waters. The California Department of Pesticide Regulation Surface Water Database (CA-SWD) was developed in 1997 to collect and provide information on pesticides in California surface waters (CDPR 2012a). Samples were taken from rivers, creeks, urban streams, agricultural drains, the San Francisco Bay delta region, and runoff of urban storm-water from August 
Table 3 Frequency of detections of chlorpyrifos in surface water samples, by Farm Resource Region (FRR) and Land-Use Class, 2002-2010

\begin{tabular}{lllllc}
\hline \multirow{2}{*}{ Region } & \multicolumn{5}{l}{ Percent detections } \\
\cline { 2 - 6 } & Agricultural & Mixed & Undeveloped & Urban & All classes \\
\hline All FRRs & 16.1 & 7.42 & 18.0 & 5.51 & 9.11 \\
Heartland & 29.8 & 6.83 & N/A $^{\mathrm{a}}$ & 6.32 & 9.40 \\
Northern Crescent & N/A & 1.59 & 0 & 0.59 & 1.05 \\
Northern Great Plains & N/A & 2.20 & 5.14 & N/A & 3.89 \\
Prairie Gateway & N/A & 2.09 & 18.8 & 9.23 & 7.19 \\
Eastern Uplands & N/A & 0.33 & 0 & 11.3 & 1.22 \\
Southern Seaboard & 1.16 & 7.31 & N/A & 4.26 & 5.81 \\
Fruitful Rim & 11.6 & 37.9 & 8.13 & 10.1 & 21.3 \\
Basin and Range & 5.00 & 1.80 & 31.3 & 0 & 22.7 \\
Mississippi Portal & 9.01 & 5.93 & 0 & 19.7 & 8.24 \\
\hline Dranyyyyy
\end{tabular}

Data from Martin et al. (2011)

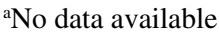

Table 4 Ninety-fifth centiles of chlorpyrifos concentrations in surface water samples, by Farm Resource Region (FRR) and Land-Use Class, 2002-2010

\begin{tabular}{llllll}
\hline \multirow{2}{*}{ Region } & \multicolumn{5}{l}{ 95th centiles of measured concentrations $\left(\mu \mathrm{g} \mathrm{L}^{-1}\right)$} \\
\cline { 2 - 6 } & Agricultural & Mixed & Undeveloped & Urban & All classes \\
\hline All FRRs & 0.0097 & 0.006 & 0.008 & 0.0067 & 0.007 \\
Heartland & 0.018 & 0.005 & N/A & 0.0076 & 0.007 \\
Northern Crescent & N/A & 0.005 & 0.005 & 0.005 & 0.005 \\
Northern Great Plains & N/A & 0.005 & 0.005 & N/A & 0.005 \\
Prairie Gateway & N/A & 0.005 & 0.009 & 0.008 & 0.0067 \\
Eastern Uplands & N/A & 0.005 & 0.005 & 10.0 & 0.005 \\
Southern Seaboard & 0.005 & 0.006 & N/A & 0.005 & 0.005 \\
Fruitful Rim & 0.0086 & 0.022 & 0.005 & 0.0098 & 0.015 \\
Basin and Range & 0.005 & 0.005 & 0.01 & 0.005 & 0.009 \\
Mississippi Portal & 0.0065 & 0.006 & 0.005 & 0.012 & 0.007 \\
\hline Data
\end{tabular}

Data from Martin et al. (2011)

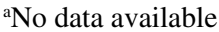

1990 through July 2010. From 2002 to 2010, the percent detections for CPY in the CA-SWD ranged from 7.6 to $27 \%$, the 95th centile concentrations ranged from 0.010 to $0.1 \mu \mathrm{g} \mathrm{L}^{-1}$, and maximum concentrations ranged from 0.15 to $3.9 \mu \mathrm{g} \mathrm{L} \mathrm{L}^{-1}$. Percent detections in the CA-SWD from 2002 to 2010 was in the same range as for the Martin et al. (2011) data, while the maximum and 95th centile concentrations were generally greater.

The majority of the applicable surface water monitoring data available in the Washington Department of Ecology's Environmental Information Management (WA-EIM) database (WDOE 2012) was generated as part of the Surface Water Monitoring Program for Pesticides in Salmonid-Bearing Streams. The monitoring program was specifically designed "to address pesticide presence in Endangered Species Act (ESA)-listed, salmonid-bearing streams during typical pesticide use periods," 
with weekly monitoring from March through October each year (WDOE 2012). As with the CA-SWD, the WA-EIM monitoring data were not suitable for trend analysis, but comparisons to the data sets of Martin et al. (2011) and CA-SWD (CDPR 2012a) could be made. From 2002 to 2011, percent detections in the WA-EIM database ranged from 4.9 to $32 \%$, rates similar to those observed by Martin et al. (2011) and CA-SWD (CDPR 2012a). The 95th centile concentrations ranged from 0.033 to $0.3 \mu \mathrm{g} \mathrm{L}^{-1}$, and maximum concentrations ranged from 0.35 to $0.59 \mu \mathrm{g} \mathrm{L}^{-1}$. In general, CPY concentrations in the EIM dataset were greater than those reported by Martin et al. (2011), but less than those reported by CA-SWD (CDPR 2012a).

Another source of information on concentrations of CPY in surface water used in this assessment was compiled by the tributary monitoring program operated by the National Center for Water Quality Research (NCWQR) at Heidelberg University (NCWQR 2012). Concentrations of nutrients, sediment, and pesticide were included in the NCWQR monitoring program database. Concentrations of CPY were reported for 6,301 samples from ten stations within the Lake Erie Basin and Ohio from 2002 to 2011. CPY was detected in 6 samples $(<1 \%)$, with concentrations ranging from 0.02 to $0.37 \mu \mathrm{g} \mathrm{L}^{-1}$. The percent of detections was less in the NCWQR dataset than in the other datasets.

Overall, the database with the greatest number of samples (more than 10,000) and broadest geographical representation (Martin et al. 2011) shows that CPY was detected in $9 \%$ of samples analyzed between 2002 and 2010 and that $95 \%$ of the samples contained CYP at less than $0.007 \mu \mathrm{g} \mathrm{L}^{-1}$, and the maximum was $0.33 \mu \mathrm{g} \mathrm{L}^{-1}$. The regional databases, which were more focused on areas of pesticide use than the USGS database, had more frequent detections (13-17\%) and greater concentrations (95th centiles $0.010-0.3 \mu \mathrm{g} \mathrm{L}^{-1}$ ). Even in the WA-EIM database, less than $1 \%$ of samples analyzed since 2007 exceeded $0.1 \mu \mathrm{g} \mathrm{L}^{-1}$.

\subsection{Chlorpyrifos in Sediment}

The NAWQA (NAWQA 2012), CA-SWD (CDPR 2012a), and WA-EIM (WDOE 2012) databases also contained data on concentrations of CPY in sediments. The NAWQA database included results of 76 analyses for CPY in sediments between 2007 and 2010 (NAWQA 2012). CPY was detected in two sediments (detection rate of $2.6 \%$ ). One sediment sample had an estimated concentration of $1 \mu \mathrm{g} \mathrm{kg}^{-1}$ and the other had a measured concentration of $58.6 \mu \mathrm{g} \mathrm{kg}^{-1}$. The LOD was $2 \mu \mathrm{g} \mathrm{kg}^{-1}$ for all samples. Data for sediment from the CA-SWD (CDPR 2012a) were only available from one study that was conducted in 2004 (Weston et al. 2005). Of 24 sediments analyzed, CPY was detected in nine, or a detection rate of $37.5 \%$. Concentrations ranged from 1.5 to $19 \mu \mathrm{g} \mathrm{kg}^{-1}$ and the limit of quantitation (LOQ) was $1 \mu \mathrm{g} \mathrm{kg}^{-1}$ for all samples. The WA-EIM database (WDOE 2012) had only one detection for CPY in 23 sediment samples (detection rate of 4.4\%) post-2001; the estimated concentration was $1 \mu \mathrm{g} \mathrm{kg}^{-1}$. 


\subsection{Chlorpyrifos Marine Monitoring Data}

Only the WA-EIM database (WDOE 2012) contained marine monitoring data. No CPY was detected in any of the 42 samples of water collected after 2001, which had method reporting limits of $0.002-0.0023 \mu \mathrm{g} \mathrm{L}^{-1}$. No sediment samples were analyzed.

\subsection{Occurrence of Chlorpyrifos Oxon}

Though not a listed USEPA contaminant (USEPA 2012), the NAWQA (NAWQA 2012), NASQAN (NASQAN 2012), CA-SWD (CDPR 2012a), and WA-EIM (WDOE 2012) databases also contained data on detections of CPYO and concentrations that provide some insight into the possible earlier distribution of CPY. The NAWQA database included results of 7,098 analyses for CPYO in surface waters between 1999 and 2012. CPYO was detected in 16 samples, a rate of $0.23 \%$. These detections, however, were all estimated concentrations, which were less than the LOQ, which ranged from 0.011 to $0.054 \mu \mathrm{g} \mathrm{L}^{-1}$. The LODs were 0.007 to $0.34 \mu \mathrm{g} \mathrm{L}^{-1}$. In instances when CPY was sampled at the same time as CPYO was detected, concentrations of CPY were less than the MDLs of 0.005 to $0.006 \mu \mathrm{g} \mathrm{L}^{-1}$ in $75 \%$ of samples (i.e., 9 of 12).

In the NASQAN database, CPYO was an analyte in 2,025 surface water samples collected between 2001 and 2012, and was detected in 9 samples-a detection rate of $0.44 \%$. Estimated concentrations ( $<\mathrm{LOQ}$ ) ranged from 0.011 to $0.036 \mu \mathrm{g} \mathrm{L}^{-1}$ and the detection limits were from 0.016 to $0.34 \mu \mathrm{g} \mathrm{L}^{-1}$. In all cases when samples were analyzed for CPY at the same time as CPYO (nine samples), concentrations of CPY were less than the MDL of 0.005 to $0.006 \mu \mathrm{g} \mathrm{L}^{-1}$. Neither the CA-SWD (CDPR 2012a) nor the EIM (WDOE 2012) databases contained any detections for CPYO in surface waters. The CA-SWD included results of 288 analyses from 2005 to 2010 ( $\mathrm{LOQ}=0.05$ to $0.06 \mu \mathrm{g} \mathrm{L}^{-1}$ ), while the EIM database contained results of 964 analyses (MDL $=0.048$ to $0.1 \mu \mathrm{g} \mathrm{L}^{-1}$ ) from 2009 to 2011 .

\subsection{Exposures in Relation to Changes in Use-Pattern}

Three different United States Geological Survey (USGS) studies used the same pesticide concentration dataset (Martin and Eberle 2009) to examine trends in pesticide concentrations in corn-belt streams (Sullivan et al. 2009), urban streams (Ryberg et al. 2010), and streams of the western U.S. (Johnson et al. 2011). The dataset containing concentrations of insecticides was compiled in the same manner as the Martin et al. (2011) dataset, which included data only from 1992 to 2008. 
Pesticide concentration trends that commonly occur in streams and rivers of the corn belt of the U.S were assessed Sullivan et al. (2009) and the relative applicability and performance several statistical methods for trend analysis were evaluated. Temporal trends in concentrations of 11 pesticides (including CPY) with sufficient data were assessed at as many as 31 stream sites for two time periods: 1996-2002 and 2000-2006. Most sites had too few concentrations that were greater than the MDLs to determine meaningful trends in CPY concentrations. All the 11 sites for which flow-adjusted trends could be analyzed during 1996-2002 exhibited downward trends in concentrations of CPY, including significant downward trends at two sites and highly significant downward trends at five sites. Only three sites could be analyzed during 2000-2006. One site had a statistically significant downward trend, the second site had a non-significant upward trend, and the third site had a highly significant upward trend. Overall, the results indicate downward trends in concentrations of pesticides in general. This included decreasing CYP concentrations in Corn Belt streams and rivers during 1996-2006, which were explained largely by the corresponding decreases in annual use due to regulatory actions or market forces.

The second USGS study (Ryberg et al. 2010) used the Martin and Eberle (2009) dataset to assess trends of pesticide concentrations in 27 urban streams in the Northeastern, Southern, Midwestern and Western regions of the U.S. Three partially-overlapping 9-yr periods (1992-2000, 1996-2004, and 2000-2008) were examined for eight herbicides, five insecticides, and three degradation products. The data were analyzed for trends in concentrations by use of a parametric regression model. Due to small and declining frequencies detection, trends in concentration of CPY were not assessable at most sites, particularly during 2000-2008. Most of the streams for which adequate data were available exhibited significant downward trends in concentrations (i.e., 10 of 11 sites during 1996-2004 and two of five sites during 2000-2008). Between 2000 and 2008, most measured concentrations of CPY were less than the MDLs and only five sites had more than 10 detections. Concentrations of CPY at two of those sites continued to decline significantly, but there were no significant downward trends at the remaining three sites during the latter period. The downward trends of CPY concentrations in urban streams were consistent with the regulatory phase-out of residential uses of CPY between 1997 and 2001 .

The most recent USGS study to use the Martin and Eberle (2009) dataset assessed trends in concentrations of two insecticides and five herbicides in 15 streams in California, Oregon, Washington, and Idaho from 1993 to 2005 (Johnson et al. 2011). Because of changes in amounts applied and methods of application in their associated catchments, pesticide concentration trends were estimated by using a parametric regression model to account for flow, seasonality, and antecedent hydrologic conditions. Short-term models of trends were developed for all sites for the period 2000-2005, while long-term models of trends were developed at 10 of the 15 study sites: two small urban sites (1996-2005), three small agricultural sites (19932005), and five large mixed land-use sites (1993-2005). Of the seven sites that had a sufficient number of uncensored (>MDL) concentrations of CPY for short-term trend analysis of flow-adjusted concentrations (2000-2005), only one site (Yakima River, WA; a large mixed land-use site) had a significant upward trend. For the 
long-term trend models, six sites had a sufficient number of uncensored concentrations of CPY for analysis of flow-adjusted concentrations. Three of the six sites had significant downward trends, one had a significant upward trend (Zollner Creek, OR; a small agricultural site), and the other two sites had no significant trends. Downward trends in concentrations of CPY at the small urban and California agricultural sites appear to reflect the phase-out of CPY and/or reduction in its use. Upward trends in the Yakima River, WA and Zollner Creek, OR might be due to increases in use from an increase in the planted acreage of certain crops (e.g., corn) and/or restrictions on the use of other organophosphate insecticides.

Overall, these three USGS analyses of the Martin and Eberle (2009) data generally indicate trends of decreasing pesticide concentrations, including CPY, in corn belt streams and rivers (Sullivan et al. 2009), urban streams in four regions of the U.S. (Ryberg et al. 2010), and in small urban and agricultural sites in California and the Pacific Northwest (Johnson et al. 2011).

\section{Modeling of Chlorpyrifos in Aquatic Environments}

Collectively, the CPY monitoring data provided useful and relevant insight towards quantifying the range of concentrations expected in surface waters. However, relatively few monitoring programs have sampled at a frequency sufficient to quantify the time-series pattern of exposure. Therefore, numerical simulations were used to characterize CPY concentrations in water and sediment for three representative high exposure environments in the United States. The environments were selected by parallel examination of use intensity across the U.S., susceptibility of CPY to runoff with respect to soil and weather variability across the U.S., and a sensitivity analysis of CPY runoff potential for various patterns of use. From the analyses, three geographical regions, each defined as several contiguous counties, were identified as having greater potential exposure to CPY. These regions were in central California, southwestern Georgia, and the Leelanau peninsula of Michigan. A small watershed, defined as having a 3rd order stream outlet, was selected from each region based on having a high density of cropland eligible for receiving CPY applications according to registered uses. Models were configured for each watershed and simulations conducted for up to $30 \mathrm{yr}$ of consecutive CPY use using historical weather records for each region modeled. Daily mean concentrations of CPY in water and sediment from runoff, erosion, and drift sources were predicted at the watershed outlets.

\subsection{Selection and Justification of the Models}

Several models were used, the number of which depended on the level of detail needed for the specific phase of the assessment. Models were selected for their ability to represent the key fate and transport processes of CPY. Based on use practices 
and chemical properties discussed in Sect. 1.1, above, potential transport pathways to aquatic systems include water and soil erosion from rainfall and irrigation and spray drift during application.

The Pesticide Root Zone Model, PRZM, was selected to evaluate pesticide runoff potential because of its ability to account for pertinent environmental processes at an appropriate spatial scale and time step for chemical dissipation. PRZM is a dynamic, compartmental model developed for simulating movement of water and chemical in unsaturated soil systems within and below the plant root zone (Carousel et al. 2005). The model simulates time-varying hydrologic behavior on a daily time step, and includes physical processes of runoff, infiltration, erosion, and evapotranspiration. The chemical transport component of PRZM calculates pesticide uptake by plants, volatilization, surface runoff, erosion, decay, vertical movement, foliar loss, dispersion and retardation. PRZM includes the ability to simulate transport of metabolites, irrigation, and hydraulic transport below the root zone. PRZM is the standard model used for ecological and drinking water pesticide risk assessments by the U.S. Environmental Protection Agency's Office of Pesticide Programs (USEPA 2009). The model has undergone extensive validation, in which the results were compared with measured concentrations from numerous studies of field-scale runoff and leaching, conducted for pesticides in the United States (Carousel et al. 2005; Jones and Russell 2001). Moreover, PRZM has been integrated into several watershed assessment models in the U.S. (Parker et al. 2007; Snyder et al. 2011).

Two versions of PRZM were used here. The majority of simulations were conducted using PRZM version 3.12.2; the version that is incorporated into the pesticide registration review process of the USA (USEPA 2009). Simulations for California were conducted using a version of WinPRZM (FOCUS 2012) that was modified (Hoogeweg et al. 2012) to simulate pesticide losses in furrow and flood irrigation tail-water, which is a significant source of pesticide loadings in many areas of California and elsewhere that utilize these irrigation practices. WinPRZM contains additional enhancements that are not available in PRZM 3.12.2 that have been added for pesticide registration evaluation in Europe, including the ability to simulate soil adsorption using the Freundlich isotherm, temperature and soilmoisture-dependent degradation, and non-equilibrium sorption to soil (FOCUS 2012). WinPRZM produces identical exposure concentrations to PRZM version 3.12.2 when those options are not used.

The Exposure Analysis Modeling System, version 2.98.04 (EXAMS), was used to evaluate the relative effects of use practices (i.e., CPY labels) on exposure concentrations. Simulations utilized standard scenarios developed by USEPA's Office of Pesticide Programs for pesticide registration review, which are configured to run with EXAMS (USEPA 2009). The scenarios represent a 10-ha field draining into a 1-ha $\times 2 \mathrm{~m}$ deep pond. EXAMS combines a chemical fate and transport model with a steady-state hydraulic model to simulate the following processes: advection, dispersion, dilution, partitioning between water, biota, and sediment, and degradation in water, biota, and sediment (Burns 2004).

The regulatory version 2.05 of the AgDRIFT ${ }^{\circledR}$ model (Teske et al. 2002) was selected to estimate spray drift deposition onto aquatic water bodies. This version of 
AgDRIFT $^{\circledR}$ contains the Tier I levels for ground and orchard air blast spraying, and the Tier I, II and III levels for aerial spraying. Tier II and III ground and orchard air blast spraying screens have not been developed. The Tier I predictions for this assessment were used for all application methods.

The 2005 version of the Soil and Water Assessment Tool (SWAT) model was chosen to link and route CPY transport in the three focus watersheds. SWAT is a semidistributed model developed by the U.S. Department of Agriculture to predict effects of land management practices on water, sediment and agricultural chemical yields in large complex watersheds that have varying soils, land use, and management conditions over long periods of time (Neitsch et al. 2010). Model components include weather, surface runoff, return flow, percolation, evapo-transpiration (ET), transmission losses, pond and reservoir storage, crop growth and irrigation, groundwater flow, reach routing, nutrient and pesticide loading, and water transfer. PRZM was used to simulate CPY in runoff and erosion, because SWAT is unable to simulate losses of CPY due to volatilization and runoff from furrow/flood irrigation tail-waters.

The Risk Assessment Tool to Evaluate Duration and Recovery (RADAR) was used to evaluate SWAT model output. RADAR is a software program commissioned by the Ecological Committee for FIFRA Risk Assessment Methods (ECOFRAM) in the late 1990s to conduct evaluations of exposure events from time-series data (ECOFRAM 1999) and to assess pulse-dose study designs. RADAR relies on the concept of defining a threshold value (or trigger value) for the water column concentration believed by the user to be of some interest in interpreting exposure. The software identifies each occurrence, in which CPY residues exceed this threshold and defines such occasion as an "event." Once an event has been triggered, the program calculates the duration that residues continue to be above this level (event duration) and then how long before the concentration again exceeds this threshold value (post-event interval).

\subsection{Chemical Input Parameter Values, Source, and Rationale}

The chemical properties used in models used in this assessment are summarized in Table 5. Selection of chemical properties began by evaluating the properties used by the U.S. Environmental Protection Agency for a dietary exposure assessment conducted in 2011 (USEPA 2011). USEPA's assessment was designed to be a conservative screening evaluation of pesticide fate and transport. However, this USEPA assessment did not adequately represent the behavior of CPY at the level of resolution and accuracy needed for the present assessment. Therefore, an expanded database on environmental fate properties was assembled and reviewed to better characterize relevant fate and transport processes.

Physicochemical properties. Available molecular weight, water solubility, and vapor pressure values were used for other elements of this risk assessment as needed (Mackay et al. 2014). PRZM simulates volatilization by using a dimensionless expression of Henry's law constant. The value provided in Table 5 was obtained 
Table 5 Environmental properties used in model simulations

\begin{tabular}{|c|c|}
\hline Property & Value used in model simulations \\
\hline Molecular weight & $350.6 \mathrm{~g} \mathrm{~mol}^{-1}$ \\
\hline Water solubility & $0.73 \mathrm{mg} \mathrm{L}^{-1}$ \\
\hline Vapor pressure & $1.87 \times 10^{-5}$ torr \\
\hline \multicolumn{2}{|l|}{ Henry's law constant } \\
\hline PRZM model & $0.5 \times 10^{-5}$ (dimensionless) \\
\hline EXAMS model & $6.2 \times 10^{-6} \mathrm{~atm} \mathrm{~m}^{3} \mathrm{~mol}^{-1}$ \\
\hline Soil adsorption / desorption, $\mathrm{K}_{\mathrm{OC}}$ & $8,216 \mathrm{~cm}^{3} \mathrm{~g}^{-1}$ (mean $\mathrm{K}_{\mathrm{OC}}$ from 37 data points) \\
\hline \multirow[t]{2}{*}{ Aerobic soil metabolism $\left(\mathrm{t}^{1} / 2\right)$} & Run 1: $28.3 \mathrm{~d}^{\mathrm{a}}$ \\
\hline & Run 2: $96.3 \mathrm{~d}^{\mathrm{a}}$ \\
\hline \multirow[t]{3}{*}{ Aqueous hydrolysis ( $\left(\mathrm{t}^{1} / 2\right)$} & $\mathrm{pH} 5: 73 \mathrm{~d}$ \\
\hline & $\mathrm{pH} 7: 81 \mathrm{~d}$ \\
\hline & $\mathrm{pH} 9: 16 \mathrm{~d}$ \\
\hline Aqueous photolysis $\left(\mathrm{t}^{1} / 2\right)$ & $29.6 \mathrm{~d}$ \\
\hline Aerobic aquatic metabolism ( $\left.\mathrm{t}^{1} / 2\right)$ & $50.8 \mathrm{~d}$ \\
\hline Anaerobic aquatic metabolism ( $\left(\mathrm{t}^{1} / 2\right)$ & $63 \mathrm{~d}$ \\
\hline Foliar degradation $\left(\mathrm{t}^{1} / 2\right)$ & $3.28 \mathrm{~d}$ \\
\hline Foliar washoff $\left(\mathrm{cm}^{-1}\right)$ & 0.1 \\
\hline Plant uptake & 0.0 \\
\hline
\end{tabular}

In the text, these numbers are rounded to whole numbers; the table values were used in the modeling

by calibration of PRZM to achieve 10-15\% loss of CPY in the first $2 \mathrm{~d}$ and $20-25 \%$ maximum after several weeks, values comparable to that reported in Sect. 1.2 and by Mackay et al. (2014). This fitted value is approximately two orders of magnitude smaller than the dimensionless values for Henry's law constants cited by the U.S. Department of Health and Health Services (USDHHS 1997) and by (Fendinger and Glotfelty 1990; Glotfelty et al. 1987; Suntio et al. 1987). Other parameters required for simulating volatilization include the diffusion coefficient of pesticide in air (DAIR) and the enthalpy of vaporization (ENPY). Values of 4,188 $\mathrm{cm}^{2} \mathrm{~d}^{-1}$ and $14.3 \mathrm{kcal} \mathrm{mol}^{-1}$ were obtained for these parameters from Carousel et al. (2005).

Soil-water partition coefficients. Soil-water partition coefficients (Kd) were calculated by multiplying the average $\mathrm{K}_{\mathrm{OC}}$ of $8,216 \mathrm{~cm}^{3} \mathrm{~g}^{-1}$ times the organic carbon content (percent) of the soil series used in a specific model simulation. The $\mathrm{K}_{\mathrm{oc}}$ value was derived as the mean value from the 37 studies presented in SI Table A4.

Soil degradation of CPY. To bracket the expected environmental behavior, model scenarios were evaluated with two soil degradation rates. As discussed in Sect. 1.2 and in Solomon et al. (2014), aerobic soil metabolism appears to be biphasic. The 28-d and 96-d half-lives represent conservative estimates for each phase. Rate constants were not adjusted for individual soils (i.e., to account for effects of hydrolysis on $\mathrm{pH}$ or photolysis).

Foliar processes. Degradation on foliar surfaces was represented by a half-life of $3.28 \mathrm{~d}$. This half-life represents the upper 90th centile confidence bound on the 
mean half-life calculated from the 18 studies of accumulation of CPY (SI Table A3). If a range of values was listed, the largest value was used in the calculation for a study (SI Table A3). If the half-life value given was expressed as being less than a given value, that value was used as a conservative estimate in the calculation. The upper 90th centile confidence bound on the mean half-life was calculated (1), (USEPA 2009) and used in the model.

$$
t_{\text {input }}=-t_{1 / 2}+\left[\frac{\left(t_{90, n} \times s\right)}{n^{1 / 2}}\right]
$$

where, $t_{\text {input }}=$ half-life input value (time) $t_{1 / 2}=$ mean of sample half-lives (time), $\mathrm{s}=$ sample standard deviation (time), $\mathrm{n}=$ number of half-live values available $(-)$, and $t_{90, n-1}=$ one-sided Student's $t$ value at $\alpha=0.1$.

A foliar wash-off fraction of $0.1 \mathrm{~cm}^{-1}$ rainfall for CPY was used in the PRZM model (Carousel et al. 2005). This value was further supported by the results of dislodgeable foliar residue studies and foliar wash-off measurements (Poletika and Robb 1994; Racke 1993). The review by Racke (1993) indicates that the proportion of applied CPY that can be washed off foliage decreases with time after application, not unexpectedly, given the large values of $\mathrm{K}_{\mathrm{OC}}$ and $\mathrm{Log} \mathrm{K}_{\mathrm{OW}}$ for CPY. Because dislodgeable residues diminish within hours after application and sampling times likely differ between studies, reported results have high variability. Relevant values of the wash-off fraction could not be derived from many of the older studies, since this would require assumptions about both the proportion of dislodgeable residue released by rain and the amount of rainfall required to release it. For example, Hurto and Prinster (cited in Racke 1993), reported dislodgeable residues on turfgrass of $0.03 \mu \mathrm{g} \mathrm{cm}^{-2}$, and total residues of 0.53 to $0.68 \mu \mathrm{g} \mathrm{cm}^{-2}$ within the first $1-2 \mathrm{~h}$ after application, giving a wash-off fraction of 0.044 to 0.057 . Since not all dislodgeable residues as measured in the laboratory (released by immersion in detergent and water) are washed off in rain, this is likely to be an overly conservative estimate. Although no information existed on the amount of rain needed to achieve such a reduction, it is likely to be substantial.

The best direct measure of foliar CPY wash-off was obtained from a field study on cotton (Poletika and Robb 1994). The results of this study (Fig. 4) show that the foliar wash-off fraction of CPY is strongly time-dependent, and has a maximum value of $\sim 0.08$ approximately $2 \mathrm{~h}$ after application. Other results that were based on irrigation of the treated area immediately after application were considered to be unrealistic. Under actual use conditions, CPY products are not to be applied when rainfall is anticipated within $2 \mathrm{~h}$ after application, since this could diminish the efficacy against foliar pests (except where the product is intentionally watered in to provide efficacy against pest in soil or thatch).

Finally, uptake of CPY by plants from the soil was considered negligible and this parameter was set to 0.0 in the model. CPY is not systemic and tends not to enter plants or move within the plant vascular system (Racke 1993). 
Fig. 4 Wash-off fraction vs. time after application

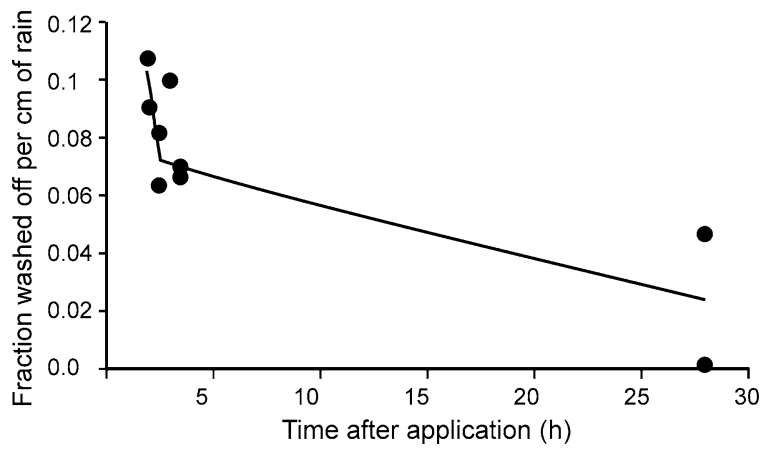

Properties of CPY in water. For the sensitivity analysis of patterns of use of CPY, degradation in the EXAMS model was regarded to occur through aerobic aquatic metabolism, aqueous hydrolysis, and photolysis. Aerobic aquatic metabolism was represented by the upper 90th centile confidence bound on the mean half-life $(\mathrm{t} 1 / 2=50.8 \mathrm{~d}$ ) calculated from (1) by using the data in SI Table A5. Aqueous hydrolysis of CYP at pH 5, 7 and 9 has been reported with half-life values of 73, 81, and $16 \mathrm{~d}$, respectively. The longer 81-d value was used for the modeling scenarios. The half-life for aqueous photolysis was taken as $29.6 \mathrm{~d}$ in the simulations. Volatilization was also simulated using the Henry's law constant of $6.2 \times 10^{-6} \mathrm{~atm} \mathrm{~m}^{3} \mathrm{~mol}^{-1}$. The calibrated dimensionless value discussed above is not applicable for aquatic media. Degradation in sediment was assumed to occur via anaerobic aquatic metabolism (63-d half-life), which was calculated from (1) by using the reported laboratory half-life values of 39 and $51 \mathrm{~d}$.

\subsection{Selection of Exposure Scenarios}

Distribution of CPY across the U.S. Intensity of use was a factor in the selection of watersheds. County sales data (Fig. 1) cannot be used to determine the precise location of product use, but it does provide a general indication of the spatial distribution of CPY use. Areas in the U.S. with the greatest intensity of use from 2010 to 2011 (depicted in blue in Fig. 1, see SI for color map) include Kern, Tulare, Santa Cruz, Fresno counties in central California; Lancaster County in southeastern Pennsylvania; and Calhoun, Decatur, and Mitchell counties in southeast Georgia. Other areas of high use at a lesser density are depicted by the green shading in Fig. 1 (see SI for color map).

National vulnerability assessment of CPY runoff. A national vulnerability assessment was conducted to characterize the potential for CPY to be transported beyond a treated field in runoff water and eroded sediment throughout the conterminous United States. The assessment involved use of the National Pesticide Tool (NPAT) to simulate the relative runoff potential of CPY for all major agricultural soil types. 
NPAT uses databases specifically created to provide access to all necessary inputs for national-scale PRZM simulation modeling, including soil location and properties, historical weather records, erosion factors, and crop parameters. A more complete description of the NPAT is provided in SI Appendix B.

It was not possible to simulate variability of areas of crops planted, application methods, rates, and intervals between applications permitted on labels at the national scale. Instead simulations were conducted with two generalized interpretations of CPY labels. Simulations used "corn/soybeans" as the crop because soybeans and corn represent approximately half of total CPY use in the U.S. One of the NPAT executions simulated a single application to soil at a unit application rate $(1.0 \mathrm{~kg}$ a.i. $\mathrm{ha}^{-1}$ ) timed at crop emergence. Properties of CPY used in the simulation are provided in Table 5 except that foliar and aquatic properties were not used in simulations and only the predominant 28-d half-life was simulated for aerobic soil metabolism. The second simulation represented two applications of CPY at $0.5 \mathrm{~kg}$ a.i. ha ${ }^{-1}$ at 21 and $35 \mathrm{~d}$ post-emergence. Properties of CPY used in the simulation are consistent with those of the soil-applied application, with the exception that foliar properties are utilized; however, volatilization from soil was not simulated because it is not as significant with foliar applications. Combined, the simulations performed included more than 64,000 combinations of soil and weather conditions for each of the two types of application considered. Each simulation was conducted for 30 consecutive years of CPY application, and used $30 \mathrm{yr}$ of historical weather data representative of the geographical location of the simulation. Daily predictions of runoff and erosion losses of CPY were estimated for each simulation and expressed as annual loads $\left(\mathrm{kg} \mathrm{ha}^{-1} \mathrm{yr}^{-1}\right)$.

The annual load calculated for the 90th centile year was used for assessment purposes. Statistics were performed using an Extended Reach File 1 (ERF) polygon basis (USEPA 2006) for mapping watersheds (Figs. 5 and 6). There are approximately 61,000 ERF polygons in the conterminous U.S.A. Each model simulation associated with a soil polygon that spatially intersects an ERF polygon was assigned a relative weight in the distribution, based on the estimated area of the soil that resides within the ERF (2).

$$
\operatorname{Prob}\left(\operatorname{Sim}_{x}\right)=A_{x} / \sum_{i=1, n}\left(A_{i}\right)
$$

Where, $\operatorname{Prob}\left(\operatorname{Sim}_{x}\right)$ is the area weighted probability associated with simulation " $x$ ", $A_{x}$ is the area associated with simulation " $x$ " that resides within the ERF, and $\sum_{i=1, n}$ $\left(A_{i}\right)$ is the area sum of the areas of all simulations that reside within the ERF.

The results of soil and foliar executions of NPAT are shown in Figs. 5 and 6, respectively. These figures present the combined runoff and erosion losses of CPY expressed as the percent of applied active ingredient at the ERF resolution. Similar patterns can be seen in Figs. 5 and 6 with the greatest losses occurring in the high summer rainfall regions on relatively heavy soils in the U.S., such as Mississippi Delta regions of Louisiana, Mississippi, and Arkansas. Relatively large losses are also concentrated in northern Missouri and bordering areas. This latter region of 


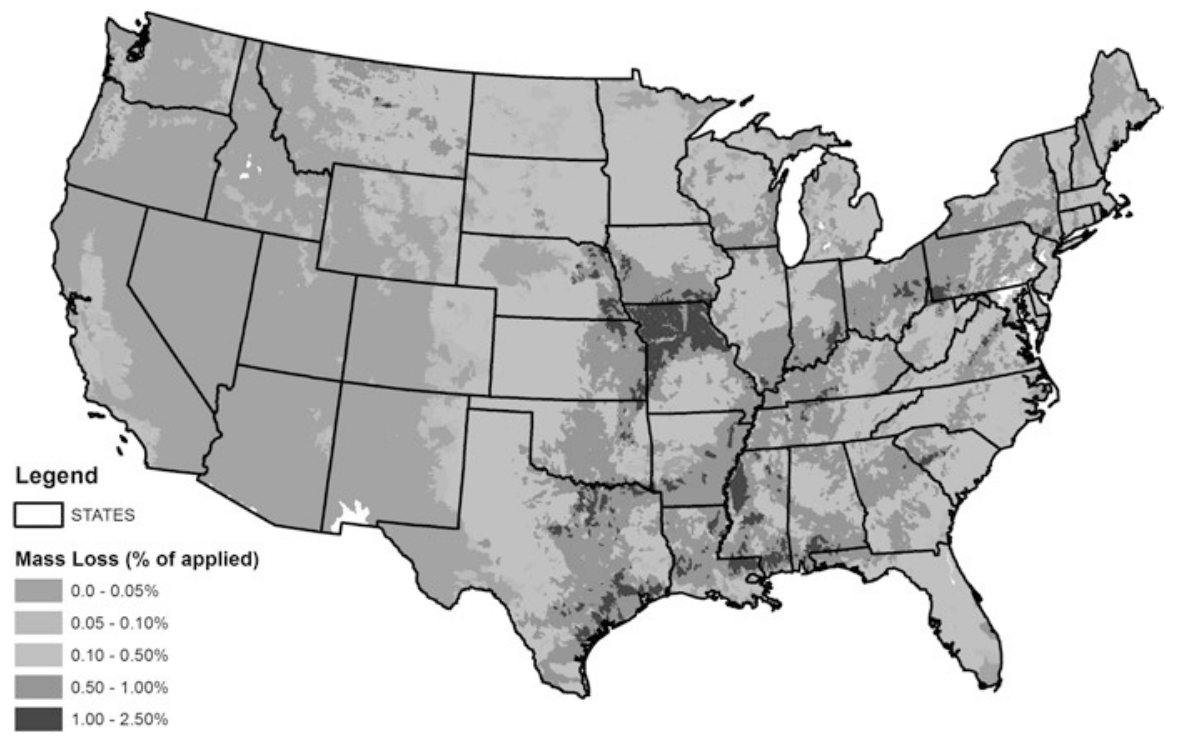

Fig. 5 Relative runoff potential of chlorpyrifos in runoff and erosion with soil applications (see SI for a color version of this Figure)

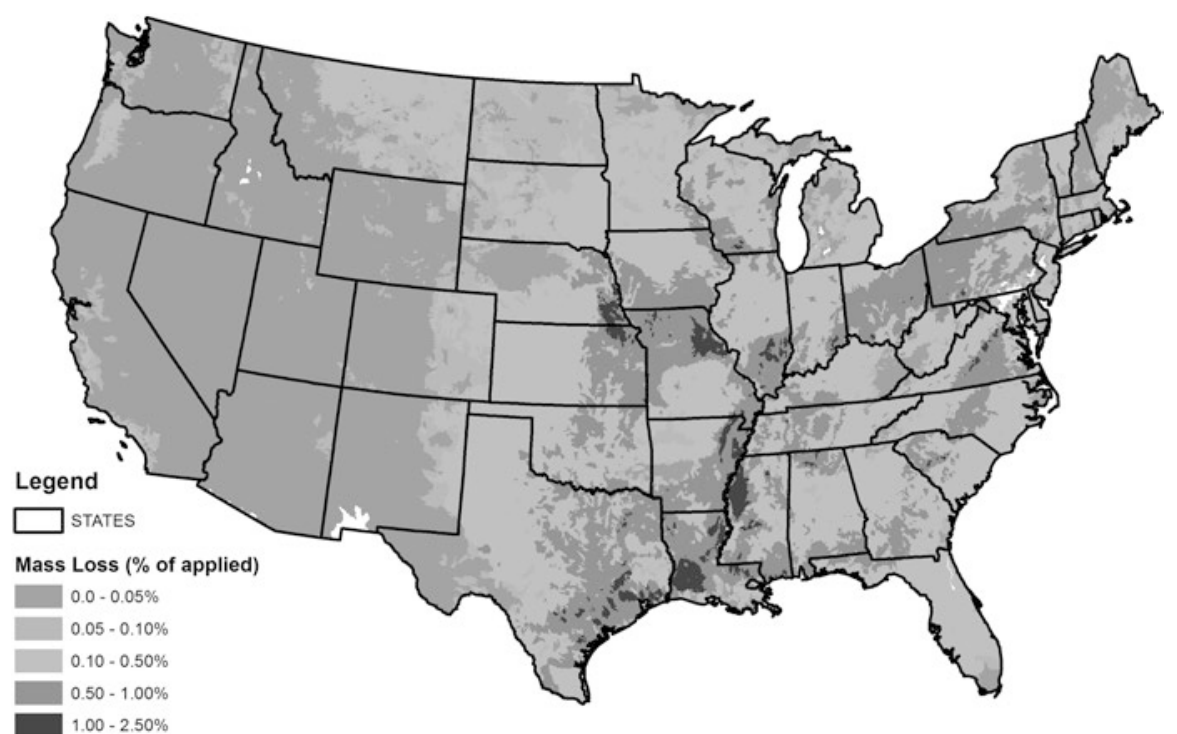

Fig. 6 Relative runoff potential of chlorpyrifos in runoff and erosion with foliar applications (see SI for a color version of this Figure) 
MO is particularly noticeable when considering soil applications of CPY (Fig. 5). Overall, runoff losses are much smaller in the more arid western states and in areas with lighter textured soil.

Sensitivity analysis of the effect of use practices on runoff of CPY. The national vulnerability assessment compared the relative runoff potentials of CPY across the U.S., based on soil properties and weather conditions. However, labels for CPY permit different use practices that cannot be assessed in a comprehensive manner at a national scale. Therefore, a sensitivity analysis was performed on use practices of CPY to determine conditions that can result in the highest potential runoff of CPY to aquatic systems. The sensitivity analysis was used to narrow the application practices and geographical areas of the country that we considered in selecting particular watersheds for more detailed analyses.

The analysis was conducted using model scenarios and procedures developed by USEPA's Office of Pesticide Programs for ecological risk assessments (USEPA 2000). The scenarios represent a hypothetical environment - a 10-ha field draining into a 1 -ha by $2-\mathrm{m}$ deep pond. The pond remains at a constant volume that receives pesticide loads from drift and runoff, but not the corresponding influx of water that would occur during a runoff event. Scenario selection began with review of a preliminary drinking water assessment of CPY conducted by USEPA (USEPA 2011). The scenarios associated with the highest exposures were selected for the sensitivity analysis: CA-grape, PA-turf, GA-pecans, MI-cherries, and FL-citrus. Several additional scenarios developed by USEPA were included in the analysis to account for other geographical areas and crops that were associated with either high use of CPY (Figs. 1 and 2) and/or high runoff potential (Figs. 5 and 6). The additional scenarios include CA-citrus, IL-corn, IN-corn, NC-corn, NE-corn, NC-apples, and NY-grape. The counties associated with these scenarios are depicted (Fig. 7).

Environmental fate properties of CPY (Table 5) and patterns of application (Table 6) developed for this study were used in the simulations. Certain application patterns for CPY were not represented correctly by USEPA (2011) in their assessment (see Racke et al. 2011) and therefore, the application patterns were reviewed and modified as necessary to better represent labeled uses. Specific items reviewed included: application methods, dates, rates, and timing. To simulate the greatest concentrations of CPY in aquatic systems, maximum label rates and minimum reapplication intervals were evaluated in the modeling. In some cases, several different application practices were represented for a specific crop location (Table 6). Two sets of simulations were conducted for each scenario-one using the shorter aerobic soil metabolism half-life value of $28 \mathrm{~d}$ and the other using a longer aerobic soil metabolism half-life value of $96 \mathrm{~d}$. The source and rationale for these chemical properties were discussed in Sect. 1.2.

Estimated environmental concentrations from the short and long aerobic soil half-live scenarios are presented in Fig. 8. Concentrations are markedly greater for certain scenarios (e.g., GA-pecan1, FL-citrus2, MI-cherries1, and IL-corn3). For other scenarios (e.g., CA-citrus3 and FL-citrus2) differences were negligible. Two scenarios (GA-pecans1 and MI-cherries1) resulted in the highest estimates of exposure concentrations and became a significant factor in selecting watersheds for the exposure assessment. 


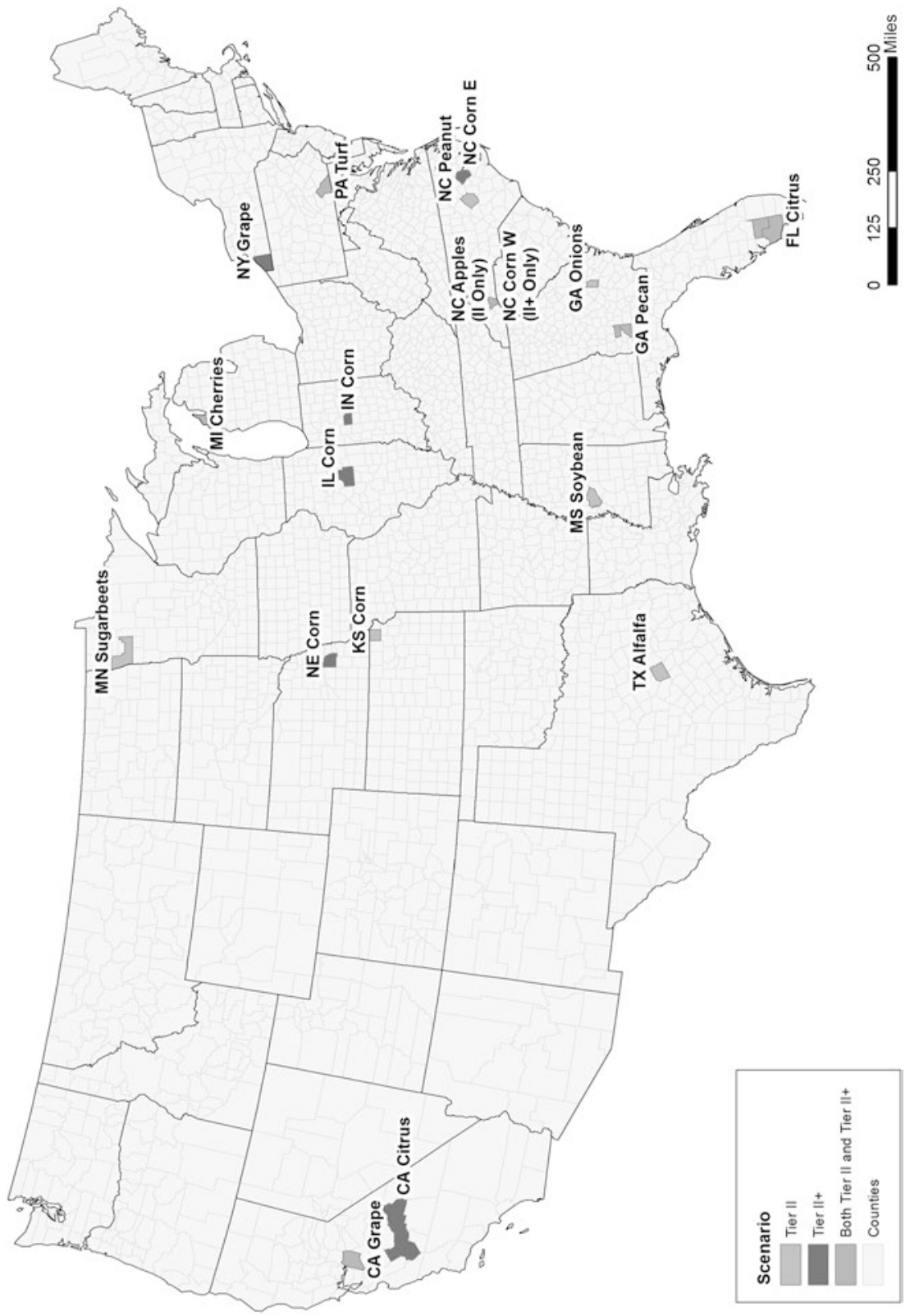

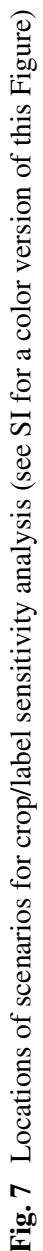




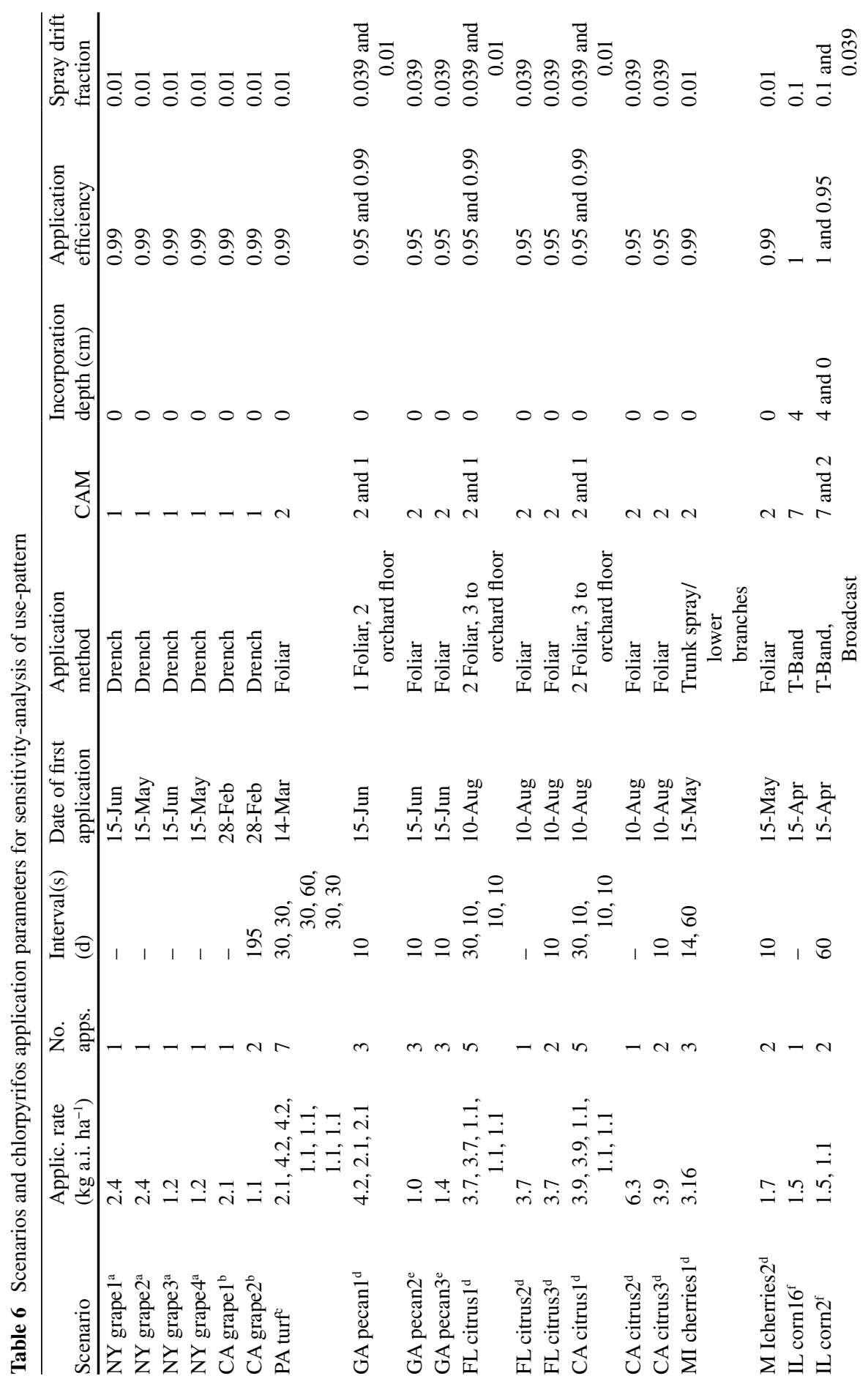




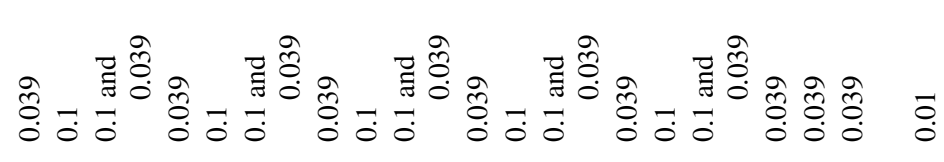

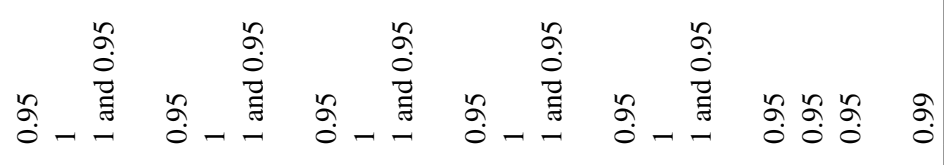

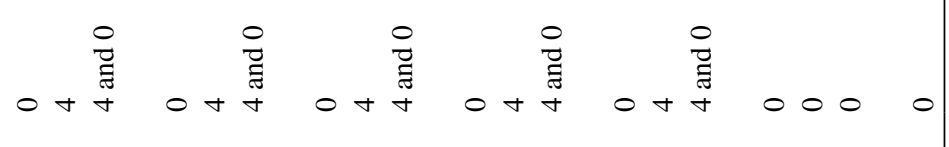

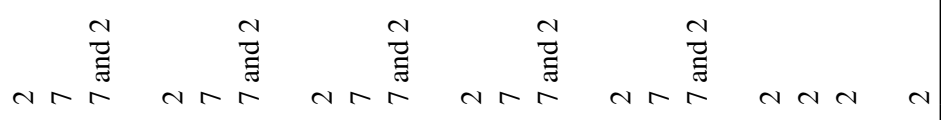

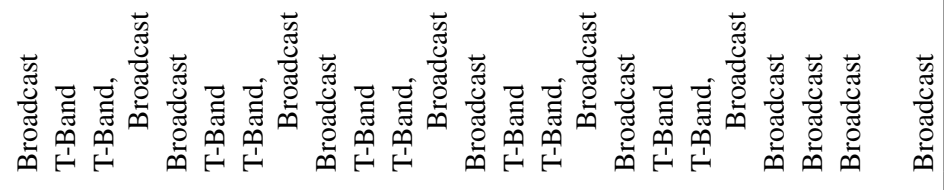

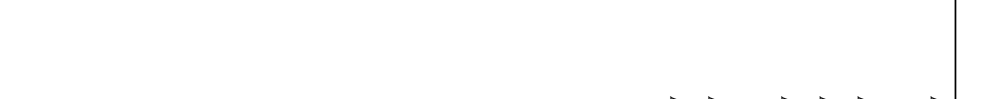

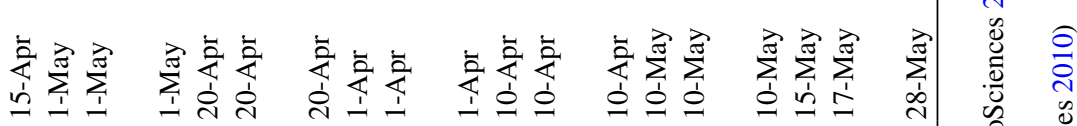

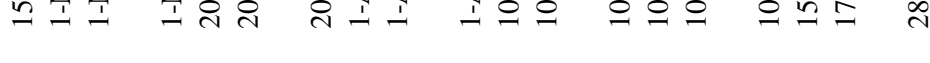

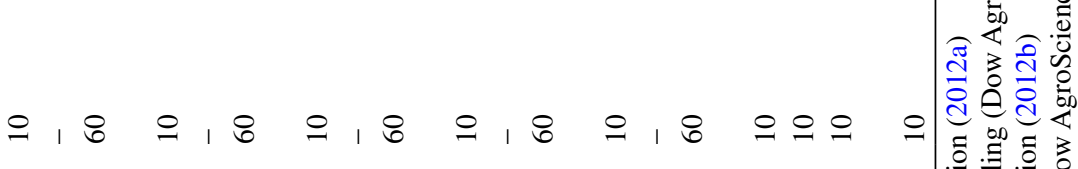

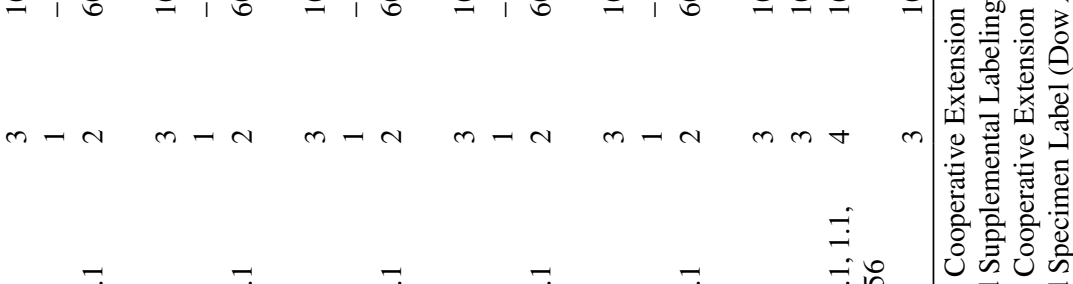

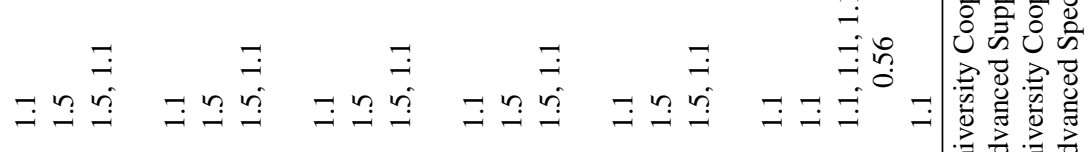

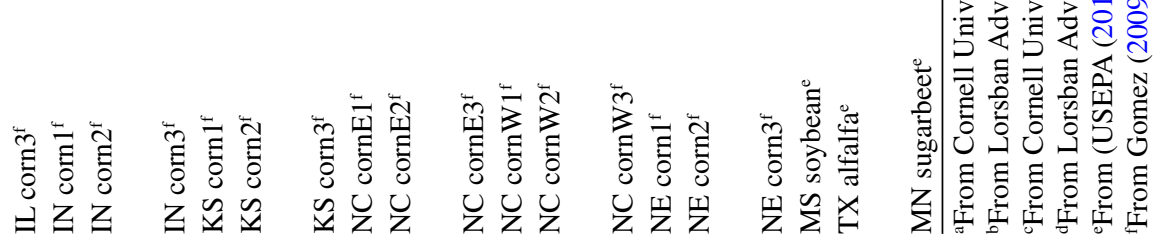




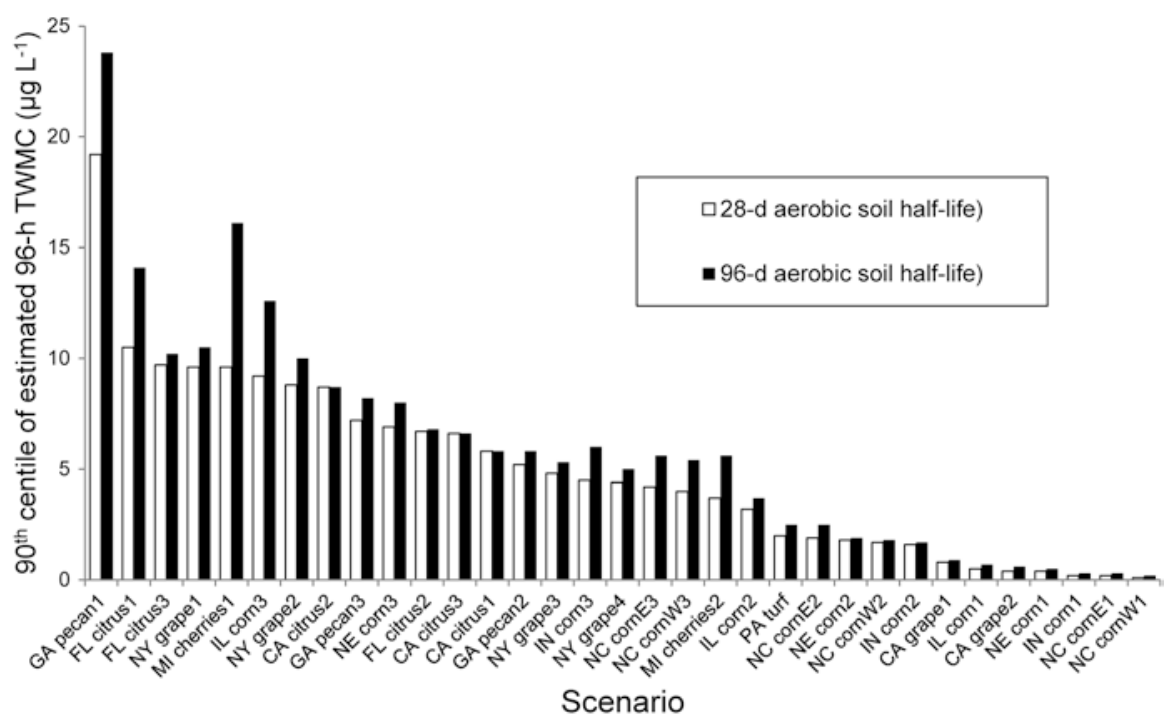

Fig. 8 Influence of aerobic soil metabolism half-life on 90th centile 96-h time-weighted mean estimated environmental concentrations for crop/label sensitivity analysis

Assessment of vulnerability for runoff of CPY in California. An assessment of vulnerability specific to California was conducted for several reasons. First, because of the large volume of CPY used in that state (Fig. 1); second, the historical detections of CPY reported from monitoring studies conducted in the state (CDPR 2012a; CEPA 2011a, b; USGS 2013); third, the availability of detailed records on pesticide applications from the California Department of Pesticide Regulation's (CDPR) Pesticide Use Reporting (PUR) database (CDPR 2012b); and fourth, because of the intensive use of furrow and flood irrigation on crops registered for use with CPY in the state (Orang et al. 2008). Losses in furrow and flood irrigation tail-water have been identified as a major cause of transport of pesticides, including CPY, to nontarget aquatic systems (Budd et al. 2009; Gill et al. 2008; Long et al. 2010; Starner et al. 2005). This pathway could not be simulated with the National Pesticide Assessment (NPAT) model.

The assessment of vulnerability for California was conducted using the Cooccurrence of Pesticides and Species Tool (CoPST), a modeling framework developed by the California Department of Water Resources (CDWR) to evaluate the potential spatial and temporal co-occurrence of pesticides with threatened or endangered aquatic and semi-aquatic species (Hoogeweg et al. 2011). The framework integrates a number of databases necessary for temporal and spatial analysis, including historical records of pesticide use and soil properties, weather records, agronomic data, and species habitat for the Sacramento River, San Joaquin, and the San Francisco Bay Delta Estuary watersheds (SI Appendix C). Using the modeling framework, daily pesticide runoff and erosion losses in the Central Valley of CA were estimated for historical CPY applications to agricultural fields. Approximately 47,860 historical applications of CPY were simulated for the period 2000-2008. 


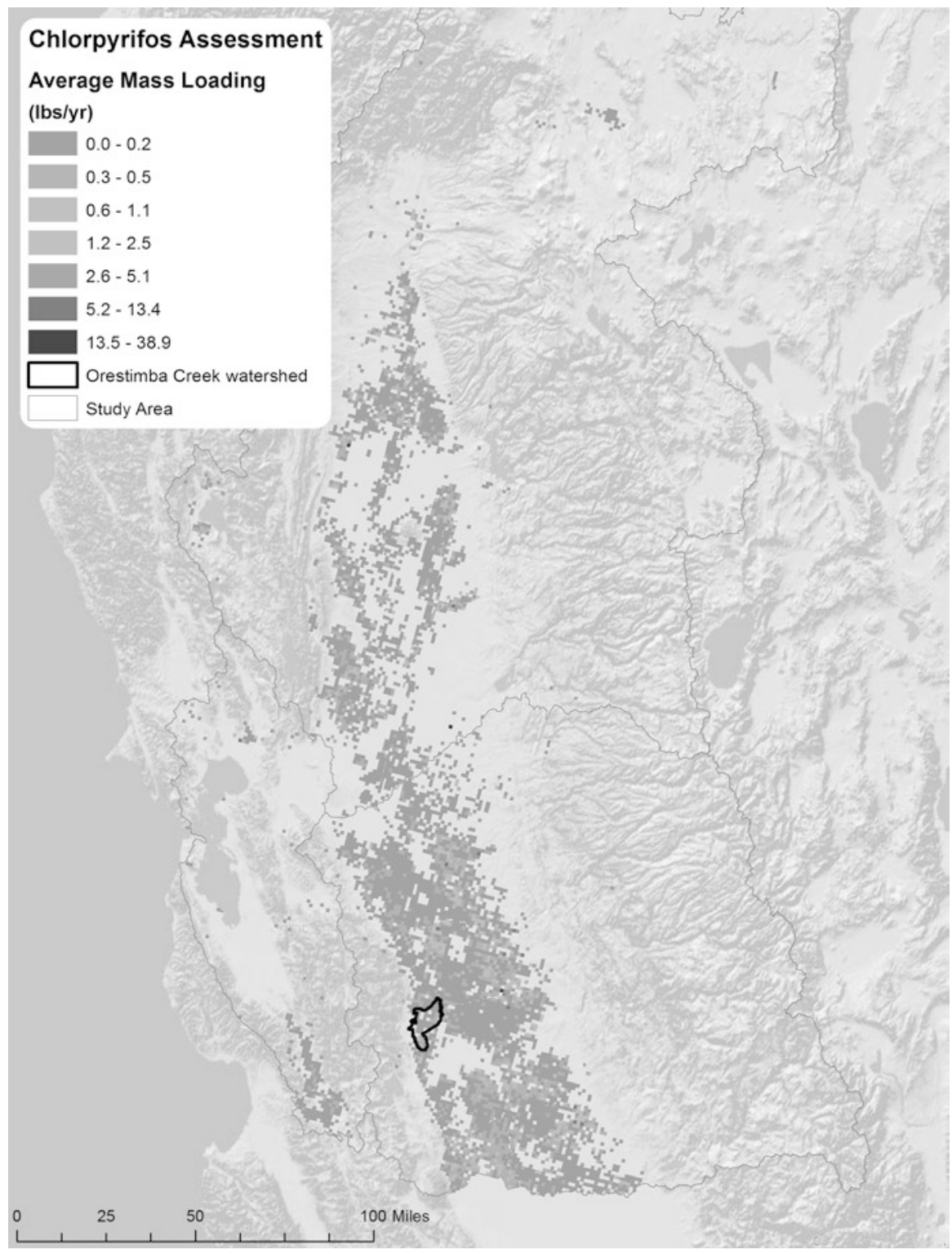

Fig. 9 Estimated average annual chlorpyrifos loss in runoff water for the Sacramento River, San Joaquin River, and Bay Delta estuary watersheds of California (see SI for a color version of this Figure)

Average annual mass loadings (Fig. 9) ranged from as little as $0.45 \mathrm{~g}$ to $18.5 \mathrm{~kg}$ per Public Land Survey Section (PLSS) per year. The largest annual mass loadings from runoff and erosion were predicted in southern Yuba County of the Sacramento Valley watershed and San Joaquin, Madera, and Stanislaus counties of the San 
Joaquin Valley watershed. Differences in loads reflect variability in crops, soils, CPY use intensity, and irrigation methods across the Central Valley.

Selection of watershed scenarios. Three geographical areas of the U.S. (southeastern Georgia, northwestern Michigan, and central California) were selected for detailed investigation. This selection was based on the parallel examination of density of use of CPY across the U.S.; the modeling study of the relative vulnerability to CPY being found in runoff with respect to soil and weather variability across the U.S.; the evaluation of use- patterns that provided the greatest estimated concentrations under a standardized scenario; and the modeling study of the relative vulnerability of CPY to runoff in California, based on detailed product-use records.

Counties in southeastern Georgia that were selected for further investigation included Mitchell, Baker, and Miller. This region was chosen because it was among those areas that sustained the highest density of CPY use in the country, it had relatively high runoff potential in the national vulnerability assessment, and had the greatest predicted exposure concentrations in the sensitivity analysis of use practices (GA-pecans). The Dry Creek watershed in the Flint River basin of Miller County (Fig. 10) was selected from this region for detailed modeling because it has a high density of labeled crops eligible for CPY applications in the region. This watershed is a third-order tributary within the Flint River watershed and drains an area of 12,322 ha. Dry creek is a predominately agricultural watershed, where $69 \%$ of the watershed is in agricultural land use (Table 7 and Fig. 10), and in which nonhay/pasture crops account for about $70 \%$ of the agricultural production area. The primary non-pasture crops (i.e., crops registered for CPY) include cotton $(21.7 \%)$, peanut $(16.3 \%)$, corn $(5.5 \%)$, and pecan $(0.6 \%)$. Most of the row crops are grown with supplemental irrigation from center pivot irrigation systems.

The Leelanau peninsula of Michigan was selected because of the high exposure concentrations estimated for the MI-cherry scenario, and that this area has one of the greatest densities of cherry orchards in the USA. The Cedar Creek watershed in the Betsie-Platte River system in Leelanau County was chosen based on having a density of labeled crops eligible for CPY applications in the region (Fig. 11). The watershed drains 7,077 ha into Lake Leelanau, which, in turn, drains directly into Lake Michigan. Land-use within the watersheds is $35 \%$ in agricultural production and $23 \%$ of the area in non-hay/pasture agriculture (Table 7 ). The primary crops in the watershed are hay $(12.0 \%)$, cherries $(11.1 \%)$, alfalfa $(8.1 \%)$, and corn $(2.7 \%)$

Orestimba Creek in the San Joaquin River basin of California (Fig. 12) was selected because of the high density of use of CPY in the watershed, frequent detections of CPY in ambient monitoring programs (Domagalski and Munday 2003; Ensminger et al. 2011; Zhang et al. 2012), and because an existing model setup of the watershed was available from the University of California (Luo et al. 2008; Luo and Zhang 2010). The watershed drains 55,998 ha from the mountainous area in the west, where brush and scrubland is predominant, into the agriculturally intensive valley floor. Overall, agriculture accounts for $22 \%$ of the total watershed area with the primary crops being walnuts, almonds, corn and alfalfa (Table 7). In the intensely cropped valley floor, agriculture accounts for over $80 \%$ of land use. In the time period from 2000 to $2008,11,658 \mathrm{~kg}$ of CPY were applied. 


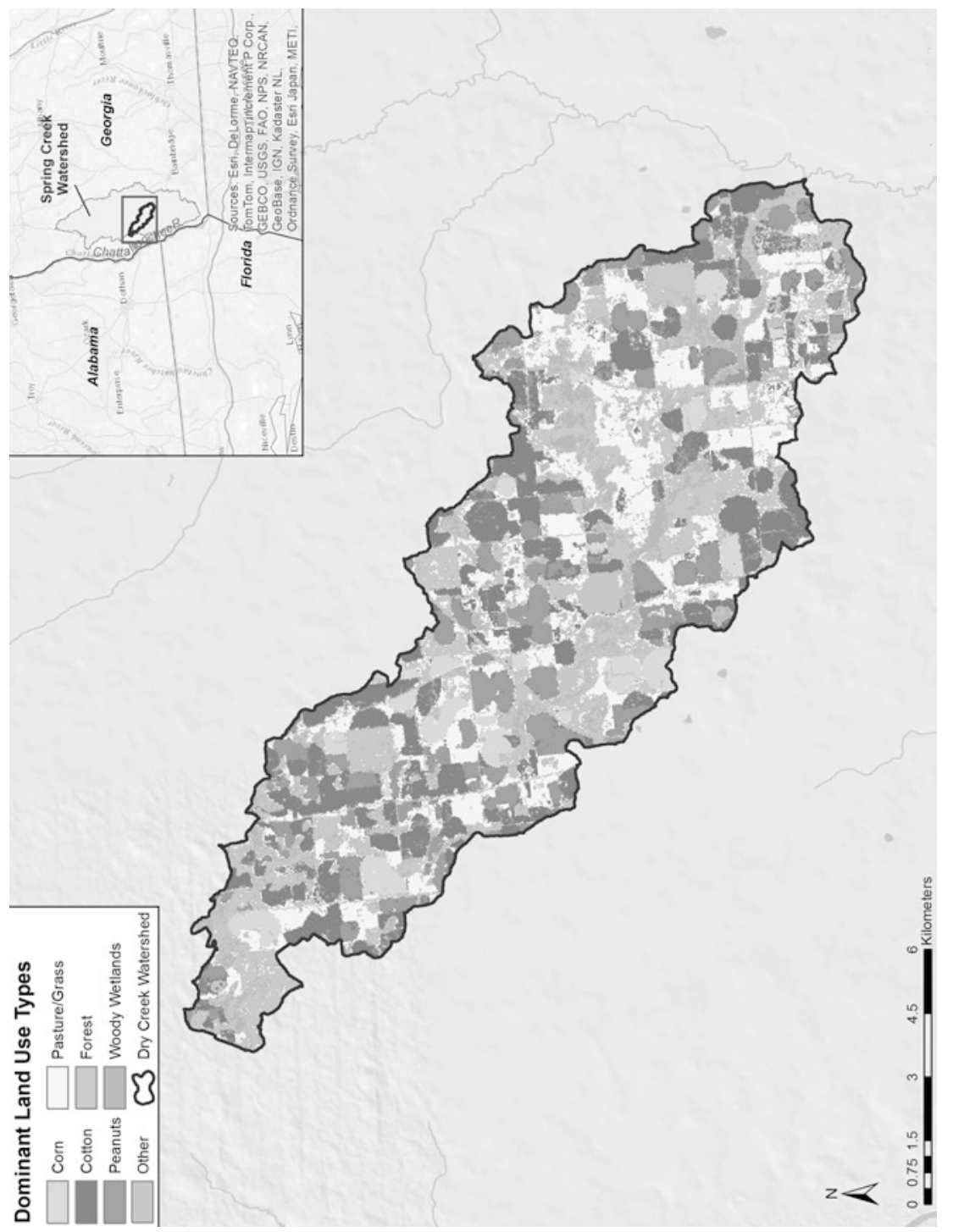

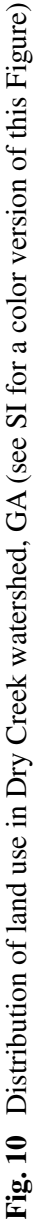


Table 7 Land use distributions in Dry Creek watershed in Georgia, Cedar Creek watershed in Michigan, and Orestimba Creek watershed in California

\begin{tabular}{lccl}
\hline \multirow{2}{*}{$\begin{array}{l}\text { Aggregated } \\
\text { land-use }\end{array}$} & $\begin{array}{l}\text { Land use distribution }(\%) \\
\text { Dry Creek watershed, } \\
\text { Georgia (12,322 ha) }\end{array}$ & $\begin{array}{l}\text { Cedar Creek watershed, } \\
\text { Michigan (6,381 ha) }\end{array}$ & $\begin{array}{l}\text { Orestimba Creek watershed, } \\
\text { California (55,997 ha) }\end{array}$ \\
\hline CPY cropland & 45.75 & 22.72 & 22.16 \\
Rangeland & 1.46 & 0.88 & 29.63 \\
Forests & 16.31 & 36.97 & 14.88 \\
Urban & 3.99 & 6.75 & 3.58 \\
Pasture / Hay & 21.26 & 12.02 & 0.00 \\
Water bodies & 0.12 & 0.07 & 0.15 \\
Wetlands & 6.35 & 20.23 & 0.91 \\
Grassland & 2.73 & 0.36 & 27.95 \\
Fallow soils & 2.04 & 0.00 & 0.74 \\
\hline
\end{tabular}

CPY cropland = crops eligible for receiving applications of CPY according to registered uses

\subsection{Watershed Scenarios}

Model Setup. The three focus watersheds (Dry Creek in Georgia, Cedar Creek in Michigan, and Orestimba Creek in California) were modeled using SWAT to simulate the daily hydrology and hydraulics and to route CPY sources in the watershed to the basin outlet. CPY runoff mass within each watershed was simulated using PRZM for Georgia and Michigan and winPRZM for California. Estimates of drift onto water surfaces were calculated from AgDrift.

The Georgia and Michigan watersheds were delineated within the SWAT 2005 ArcView interface by using local $10 \mathrm{~m}$ digital elevation model (DEM) GIS data from the National Elevation Dataset (NED) and hydrography datasets from the area. These data were downloaded from the US Geological Survey available through the National Map data server (http://nationalmap.gov/viewer.html) (Gesch 2007). Land cover/use for the locations was mapped within the model from the USDA National Agriculture Statistics Service Cropland Data Layer (USDA 2012). The watersheds were subdivided in sub-basins, primarily at stream confluences, and an area threshold was used to include hydrologic response units (combinations of soils and land uses) that accounted for more than $5 \%$ of the watershed area. This threshold was used as a filter to aid in computational efficiency so that not every land use and soil combination is simulated. Datasets of rainfall and max/min temperature from local weather records were used to drive the hydrologic simulations. Simulations for the Georgia and Michigan watersheds were simulated for the $30-\mathrm{yr}$ period of 1961-1990.

To provide for a conservative assessment, all cropland eligible for CPY applications according to product labels in the Dry Creek and Cedar Creek watersheds were represented as "GA-pecan1" or "MI-cherries1". For example, areas designated as pecan, cotton, sorghum, corn, peanut, and peaches in the Dry Creek watershed were represented as GA-pecan1, with respect to soil, crop, and CPY application 


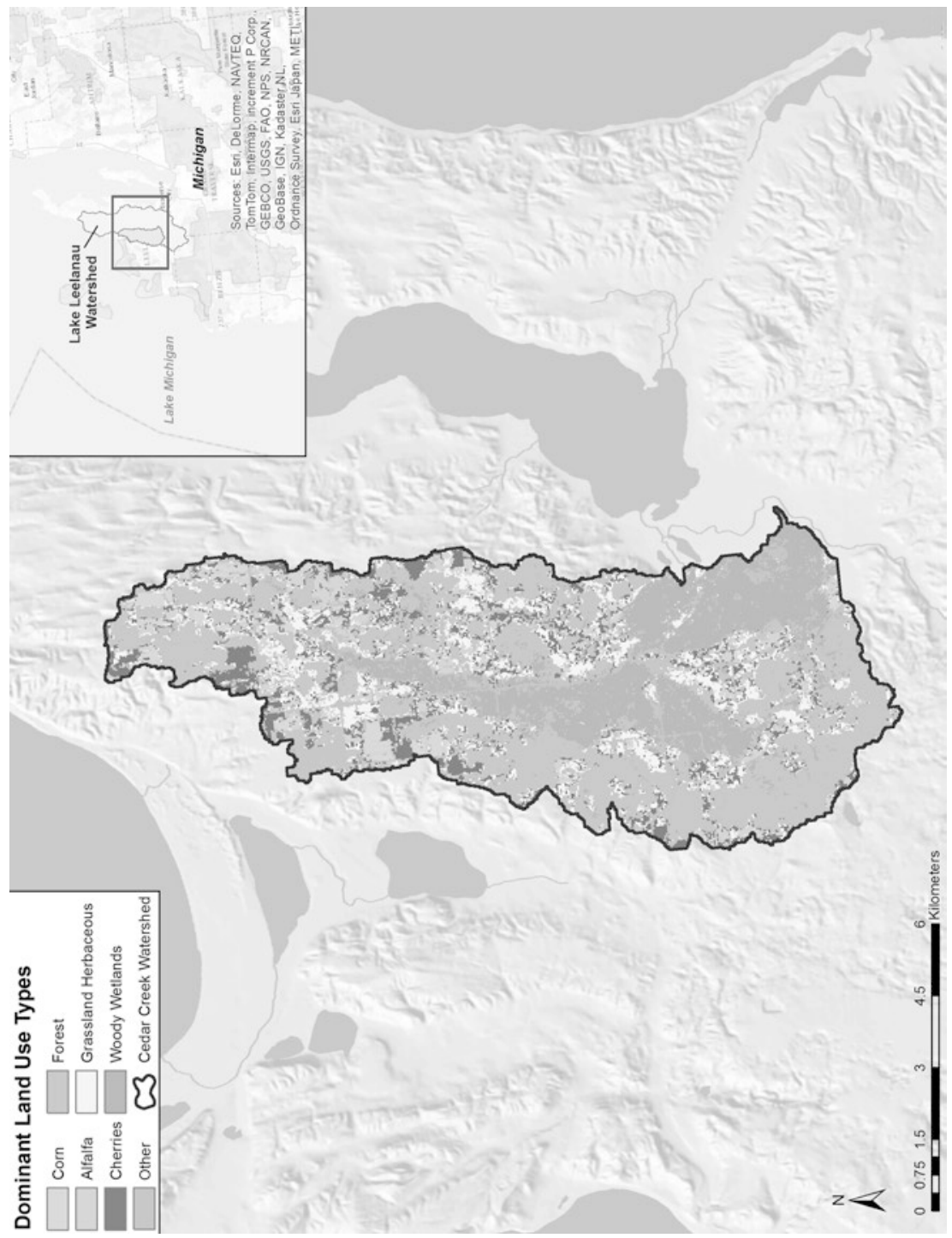




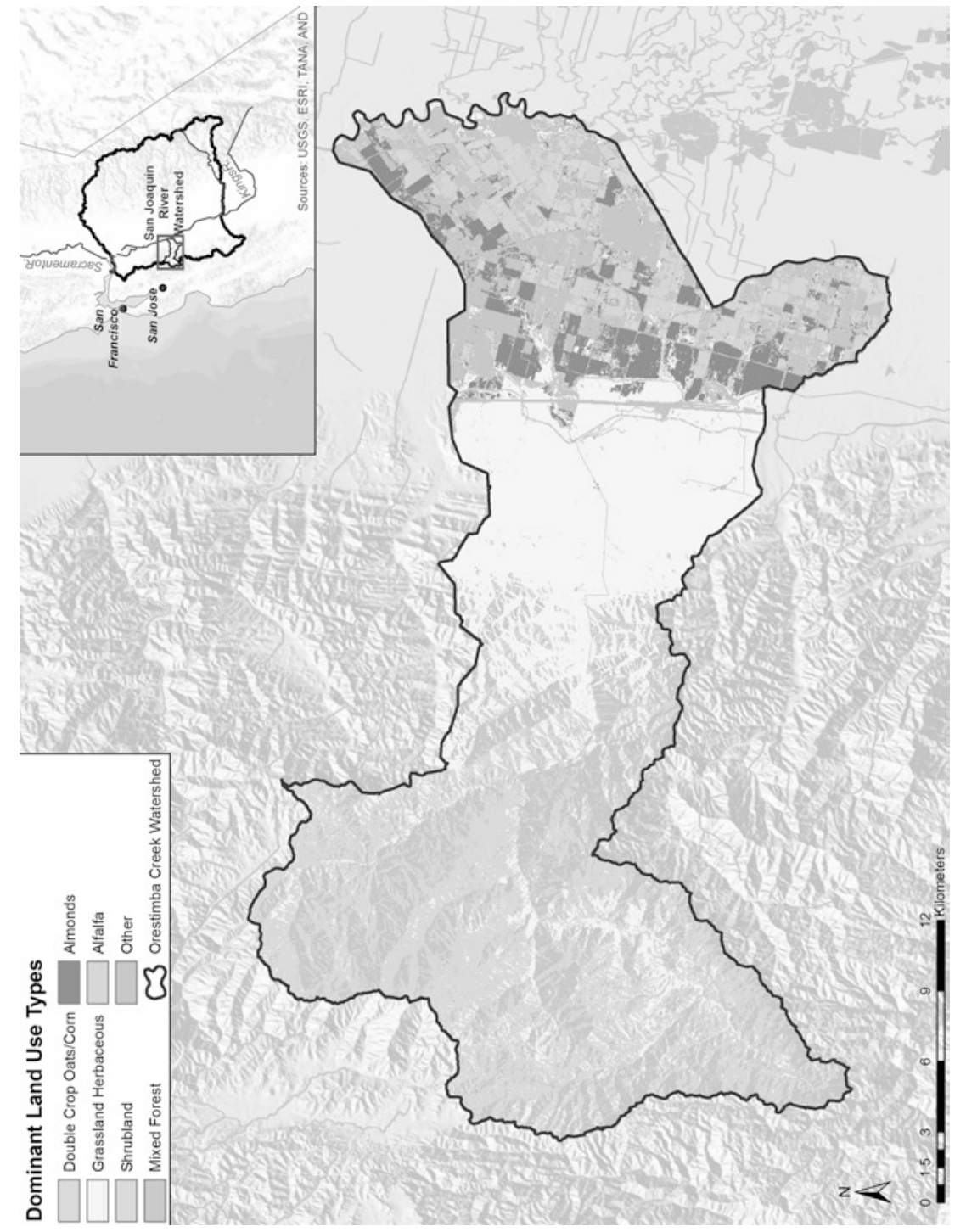

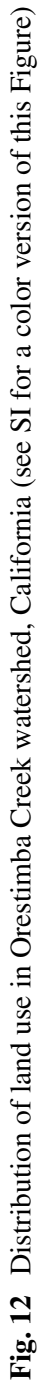


rates, methods, and intervals between applications. Similarly, all eligible cropland in Cedar Creek was represented as the MI-cherries1 scenario. The applications were scheduled to occur over a 7-d application window to represent the reality that not all fields in a 7,000-12,000 ha watershed can receive applications on the same day.

An additional adjustment was made to the plant growth parameters for the Cedar Creek scenarios. In practice, applications of chlorpyrifos on cherries are directed to tree trunks and lower branches. With tart cherries, foliage may also be sprayed. The crop emergence and maturation dates in USEPA's scenario for MI-cherries resulted in an unrealistic 18, 47, and $0 \%$ of the CYP applied being depositing on the trees and 82,53 , and $100 \%$ on soil for each of the three applications per year, respectively. To simulate a more realistic proportion of deposition of chemical on the trees, the maximum canopy and maturity and harvest dates were modified to achieve deposition of $80 \%$ of the a.i. applied on the trees and $20 \%$ on the soil for all three applications.

Inputs of CPY for the California model were calculated slightly differently from the Georgia and Michigan watersheds. Applications of CPY were specific to the date, crop, and PLSS location in the California Pesticide Use Reporting database (CDPR 2012b). The California simulations were simulated for the more recent 9-yr period of 2000-2008 during which there were 293 actual CPY applications across the watershed.

Drift of CPY onto water surfaces was estimated with the AgDRIFT model to account for setback requirements on product labels. The ground spray was assumed to be applied with a $7.6 \mathrm{~m}(25-\mathrm{ft})$ spray buffer, high boom, and a fine to medium/ coarse spray. Aerial spray was assumed to have a $45.7 \mathrm{~m}$ (150-ft) spray buffer and medium to coarse spray. Orchard applications were represented as an aerial spray (45.7 $\mathrm{m}$ spray buffer), because airblast (15.2 $\mathrm{m}$ spray buffer) is not specifically identified in the PUR database as an application method. Boom height and droplet sizes that result in the greatest drift allowed on CPY use labels were assumed. The proximity of treated fields to water was unknown, and therefore the area of surface water receiving spray drift was assumed to be in direct proportion of the watershed land area receiving applications.

Chemical properties used in the simulations of Dry Creek, Cedar Creek, and Orestimba Creek are summarized in Table 3. Two sets of simulations were conducted for each watershed using the 28-d and 96-d aerobic soil metabolism halflives. Foliar degradation was not represented in the Orestimba Creek simulations because of occasional model crashes that prevented completion of the full set of simulations. Results are conservative for applications that occur to foliage for Orestimba Creek.

Daily estimates of masses of soluble and sediment-bound CPY were predicted at the outlet of each watershed with SWAT. Soluble mass values were converted to concentrations by dividing the mass of the soluble CPY $(\mathrm{mg})$ by the volume of stream flow (L) for the day. Concentrations of sediment-bound CPY were calculated from the ratio of the daily bed load CPY mass (mg) to the mass of bed sediment in the outlet reach, assuming an active sediment layer of $3 \mathrm{~cm}$ (length of reach $\times$ width of reach $\times 0.03 \mathrm{~m}$ depth of sediment bed). 
Table 8 Characteristics of modeled 96-h time-weighted mean chlorpyrifos concentrations in water draining the focus watersheds

\begin{tabular}{|c|c|c|c|c|c|}
\hline \multirow{3}{*}{$\begin{array}{l}\text { Location of } \\
\text { watershed }\end{array}$} & & \multirow{2}{*}{\multicolumn{2}{|c|}{$\begin{array}{l}\text { Concentration } \\
\text { in water }\left(\mu \mathrm{g} \mathrm{L}^{-1}\right) \\
\text { Half-life }\end{array}$}} & \multirow{2}{*}{\multicolumn{2}{|c|}{$\begin{array}{l}\text { Concentration in } \\
\text { sediment }\left(\mu \mathrm{g} \mathrm{kg}^{-1}\right) \\
\text { Half-life }\end{array}$}} \\
\hline & & & & & \\
\hline & & $28-d$ & 96-d & $28-d$ & $96-d$ \\
\hline \multirow[t]{4}{*}{ California } & Minimum & 0.003 & 0.013 & 4.74 & 10.8 \\
\hline & Median & 0.024 & 0.251 & 7.91 & 14.6 \\
\hline & 90th centile & 1.319 & 1.543 & 10.8 & 20.8 \\
\hline & Maximum & 1.392 & 2.142 & 11.0 & 22.2 \\
\hline \multirow[t]{4}{*}{ Georgia } & Minimum & 0.004 & 0.004 & 0.007 & 0.007 \\
\hline & Median & 0.010 & 0.010 & 0.023 & 0.027 \\
\hline & 90th centile & 0.020 & 0.020 & 0.050 & 0.060 \\
\hline & Maximum & 0.023 & 0.023 & 0.064 & 0.067 \\
\hline \multirow[t]{4}{*}{ Michigan } & Minimum & 0.002 & 0.007 & 0.027 & 0.010 \\
\hline & Median & 0.011 & 0.018 & 0.021 & 0.038 \\
\hline & 90th centile & 0.018 & 0.034 & 0.032 & 0.060 \\
\hline & Maximum & 0.028 & 0.043 & 0.047 & 0.074 \\
\hline
\end{tabular}

Values reflect the 90th centile of the annual maxima (1 in $10 \mathrm{yr}$ maximum value)

Annual maximum concentrations. A probability analysis was conducted on the daily time-series predictions of CPY concentrations in the water and sediment for each watershed using the RADAR program (SI Appendix E). RADAR converts a daily time series to an annual maximum series for various exposure durations that are based on a rolling average calculation. The durations of exposure included the instantaneous maximum, 96-h, 21-d, 60-d, and 90-d average concentrations.

Maximum daily concentrations predicted for the California, Georgia, and Michigan watersheds were 3.2, 0.041, and $0.073 \mu \mathrm{g} \mathrm{L}^{-1}$, respectively, with the 28-d aerobic soil metabolism half-life and 4.5, 0.042, and $0.122 \mu \mathrm{g} \mathrm{L}^{-1}$, respectively, with the 96-d soil half-life. For sediments, the maximum daily concentrations predicted for the California, Georgia, and Michigan watersheds were 11.2, 0.077, and 0.058 $\mu \mathrm{g} \mathrm{kg}{ }^{-1}$, respectively, with the 28-d half-life and $22.8,0.080$, and $0.087 \mu \mathrm{g} \mathrm{kg}^{-1}$, respectively, with the 96-d soil half-life. The 96-h time weighted mean concentrations (TWMC), used in the risk assessment (Giddings et al. 2014) are summarized in Table 8. Concentrations associated with the minimum year, median year, 90th centile year, and maximum year are presented. Annual maxima concentrations for all years are provided in SI Appendix D.

The greatest annual concentrations of CPY in water and sediment were predicted in the California watershed, using the 96-d aerobic soil metabolism half-life. Predicted concentrations in water ranged from 0.003 to $1.39 \mu \mathrm{g} \mathrm{\textrm {L } ^ { - 1 }}$ for the $28-\mathrm{d}$ half-life simulations, increasing slightly to a range of $0.013-2.14 \mu \mathrm{g} \mathrm{L}^{-1}$ for the $96-\mathrm{d}$ half-life simulations. Similarly, CPY concentrations in sediment ranged from 4.74 to $11.0 \mu \mathrm{g} \mathrm{kg}^{-1}$ in simulations that used 28 -d half-life, and $10.8-22.2 \mu \mathrm{g} \mathrm{kg}^{-1}$ in simulations that used a half-life of 96-d. Predicted annual concentrations in the Georgia and Michigan watersheds were less than those for California. The Georgia watershed had a maximum 96-h TWMC of $0.023 \mu \mathrm{g} \mathrm{L}^{-1}$ in water for the $28-\mathrm{d}$ and 
Table 9 Duration of exposures events in the focus watersheds for the 30-yr simulation period

\begin{tabular}{lllllcc}
\hline Location of watershed & Georgia & \multicolumn{3}{l}{ Michigan } & \multicolumn{2}{c}{ California } \\
\hline Event threshold $\mu \mathrm{g} \mathrm{L}^{-1}$ & 0.1 & 1.0 & 0.1 & 1.0 & 0.1 & 1.0 \\
Duration of events for 28-d half-life & & & & & & \\
No. of events & 0.0 & 0.0 & 0.0 & 0.0 & 10 & 4 \\
Min. duration (d) & $\mathrm{n} / \mathrm{a}$ & $\mathrm{n} / \mathrm{a}$ & $\mathrm{n} / \mathrm{a}$ & $\mathrm{n} / \mathrm{a}$ & 1 & 1 \\
Max. duration (d) & $\mathrm{n} / \mathrm{a}$ & $\mathrm{n} / \mathrm{a}$ & $\mathrm{n} / \mathrm{a}$ & $\mathrm{n} / \mathrm{a}$ & 11 & 2 \\
Median duration (d) & $\mathrm{n} / \mathrm{a}$ & $\mathrm{n} / \mathrm{a}$ & $\mathrm{n} / \mathrm{a}$ & $\mathrm{n} / \mathrm{a}$ & 1 & 1.5 \\
Avg. duration (d) & $\mathrm{n} / \mathrm{a}$ & $\mathrm{n} / \mathrm{a}$ & $\mathrm{n} / \mathrm{a}$ & $\mathrm{n} / \mathrm{a}$ & 2.9 & 1.5 \\
Duration of events for 96-d half-life & & & & & & \\
No. of events & 0.0 & 0.0 & 3 & 0.0 & 35 & 10 \\
Min. duration (d) & $\mathrm{n} / \mathrm{a}$ & $\mathrm{n} / \mathrm{a}$ & 1 & $\mathrm{n} / \mathrm{a}$ & 1 & 1 \\
Max. duration (d) & $\mathrm{n} / \mathrm{a}$ & $\mathrm{n} / \mathrm{a}$ & 1 & $\mathrm{n} / \mathrm{a}$ & 15 & 6 \\
Median duration (d) & $\mathrm{n} / \mathrm{a}$ & $\mathrm{n} / \mathrm{a}$ & 1 & $\mathrm{n} / \mathrm{a}$ & 1 & 1 \\
Avg. duration (d) & $\mathrm{n} / \mathrm{a}$ & $\mathrm{n} / \mathrm{a}$ & 1 & $\mathrm{n} / \mathrm{a}$ & 2.3 & 1.9 \\
\hline & & & & & &
\end{tabular}

96-d half-life simulations. The maximum 96-h TWMCs in sediment were $0.064 \mu \mathrm{g} \mathrm{kg}^{-1}$ and $0.067 \mu \mathrm{g} \mathrm{kg}^{-1}$ in the $28-\mathrm{d}$ and 96-d half-life simulations, respectively. The Michigan watershed had a maximum 96-h TWMC of $0.028 \mu \mathrm{g} \mathrm{L}^{-1}$ and $0.043 \mu \mathrm{g} \mathrm{L}^{-1}$ in water for the 28-d and 96-d half-life simulations, respectively. Maximum 96-h TWMCs in sediment were $0.047 \mu \mathrm{g} \mathrm{kg}^{-1}$ and $0.074 \mu \mathrm{g} \mathrm{kg}^{-1}$ in the 28-d and 96-d half-life simulations, respectively.

Event duration analysis. Using RADAR, characterization of durations of exposure events was conducted on each time series record by using concentration thresholds of 0.1 and $1.0 \mu \mathrm{g} \mathrm{L}^{-1}$ for the three watersheds. In Table 9, we list each event that met the respective criteria for the model simulations using both half-life assumptions. Additional information on each event, including the maximum duration of the event, average concentration during the event, and the date when the event began are provided in SI Appendix E.

There were no events exceeding the concentration threshold for the Georgia watershed over the 30-yr simulation period with either the 28-d or 96-d half-life values. For the Michigan watershed, no events were predicted with the 28-d half-life and three events were predicted with the 96-d half-life. All three events were limited to $1 \mathrm{~d}$. California was predicted to have the greatest number of exceedance events. At a $0.1 \mu \mathrm{g} \mathrm{L} \mathrm{L}^{-1}$ threshold, 10 events were predicted to occur with the 28-d half-life life, while 35 occurred with the 96-d half-life. For the 96-d half-life and the $0.1 \mu \mathrm{g} \mathrm{L}^{-1}$ threshold, the median event duration was $1 \mathrm{~d}$ and the longest duration was $15 \mathrm{~d}$.

\section{Discussion}

CPY is not detected frequently or at large concentrations in surface waters of the U.S. Monitoring data reported in the USGS, CDPR, and WDOE databases indicate maximum water $\mathrm{CPY}$ concentrations ranging from 0.33 to $3.96 \mu \mathrm{g} \mathrm{L}^{-1}$. These 
maxima represent approximately 17,700 sample analyses (911 locations) during 2002-2010 that were collected following the ban on residential uses and other label changes of CPY ca. 2001. However, detections are relatively infrequent. Characterization of surface water CPY concentrations in this 9-yr period from regional data sets that focused on use areas indicated that only $13-17 \%$ of collected samples contained detectable CPY concentrations. The 95th centile concentrations from these programs ranged from $<0.01$ to $0.3 \mu \mathrm{g} \mathrm{L}-1$ across years.

Similarly, CPYO was not detected frequently or in large concentrations. The databases of the USGS, CDPR, and WDOE contained reports of only 25 detections of CPYO from 10,375 analyses ( $0.24 \%$ of samples) in surface water between 1999 and 2012. The concentrations reported in the 16 detections reported in the USGS databases $(9,123)$ were all below the LOQ and neither the CDPR nor the WDOE databases contained any reports of detections of CPYO in surface waters.

One of the inherent limitations of monitoring data is that it may not be wholly representative of all locations. Because of logistical and resource issues, not all locations can be sampled with a frequency and duration that fully characterizes peaks in exposures, especially those of short duration. Thus, modeling was used to provide estimates of concentrations in surface waters across the country. From knowledge of rates of and frequency of application, environmental settings were identified as being more susceptible to runoff and CPY drift into surface water. These included areas of higher rainfall and heavier soils and those receiving the greatest single application rate or shortest intervals between multiple applications as identified from the sensitivity analysis of use-patterns.

Because it was not possible to model all locations in detail and all scenarios of CPY use in the USA, the analyses of sensitivity were used to identify three focus watersheds-Dry Creek in Georgia, Cedar Creek in Michigan, and Orestimba Creek in California. These watersheds were intended to provide realistic but reasonable worst-case predictions of concentrations of CPY in runoff water and sediment. The soil-water hydrologic model SWAT was combined with PRZM to predict these concentrations using a 30-y climatic record (1961-1990 for Dry Creek and Cedar Creek and 2000-2008 for Orestimba Creek) and local cropping and soils information. Two half-lives for aerobic soil metabolism of CPY in soil, 28 and $96 \mathrm{~d}$, were selected for the purposes of modeling.

Estimated concentrations of CPY in water for the three watersheds were in general agreement with ambient monitoring data from 2002 to 2010 in the datasets of the USGS, CDPR, and WDOE. Maximum daily concentrations predicted for the California, Georgia, and Michigan watersheds were 3.2, 0.041 , and $0.073 \mu \mathrm{g} \mathrm{L}^{-1}$, respectively, with the 28-d aerobic soil metabolism half-life and 4.5,0.042, and $0.122 \mu \mathrm{g} \mathrm{L}{ }^{-1}$, respectively, with the 96-d soil half-life. These compared favorably with maximum concentrations measured in surface water, which ranged from 0.33 to $3.96 \mu \mathrm{g} \mathrm{L}^{-1}$. For sediments, the maximum daily concentrations predicted for the California, Georgia, and Michigan watersheds were $11.2,0.077$, and $0.058 \mu \mathrm{g} \mathrm{kg}^{-1}$, respectively, with the 28 -d half-life and $22.8,0.080$, and $0.087 \mu \mathrm{g} \mathrm{kg}^{-1}$, respectively, with the 96-d soil half-life. Twelve detections out of 123 analyses were contained in the USGS, CDPR, and WDOE databases with concentrations reported from $<2.0$, up to $19 \mu \mathrm{g} \mathrm{kg}^{-1}$ with the exception of one value reported at $58.6 \mu \mathrm{g} \mathrm{kg}^{-1}$. Again, the 
modeled values compared favorably with measured values. Duration and recovery intervals between CPY water concentrations that exceeded two different threshold values derived from toxicity data of Giddings et al. (2014) were also computed. Based on modeling with the half-life of $28 \mathrm{~d}$, no exceedances were identified in the focus watersheds in Georgia or Michigan. Using the half-life of $96 \mathrm{~d}$, only three exceedance events of 1-d duration each were identified in the Michigan focuswatershed. Frequency of exceedance was greater in the focus watershed from California. There were 10-35 exceedance events (depending on threshold level) during the 30-yr simulation period, or an average of less than one per year. Moreover, even in this worst-case focus-watershed, the median event exceedance duration was $1 \mathrm{~d}$. The greater concentrations in Orestimba Creek are attributed to a higher frequency of applications, a higher frequency of runoff events (due to irrigation tailwater), and less stream-flow for dilution.

Several advantages and insights gained from the modeling of concentrations of CPY in surface waters were developed from range of modeling assumptions and field conditions simulated. Conservative assumptions were used in the modeling of concentrations in the focus-watersheds. Studies on environmental-fate of CPY have demonstrated a range of rates of degradation in soil, crops, and aquatic systems. Values from these data were selected to represent appropriate degradation and loss processes in the modeling. For example, the 90th centile confidence interval on the mean half-life was selected to err on the side of caution. Conservative assumptions were also used in configuring the Georgia and Michigan watersheds, in that all eligible crop acreage in each watershed was represented as if it were pecan or cherries, respectively; thereby, the soil properties and applications of CPY represented by the use-pattern selected produced the greatest estimates of exposure-concentrations. Model simulations for Orestimba Creek used reported applications of CPY, but field specific management practices to mitigate runoff and drift were not represented in the simulations. In addition, volatilization was not included in the California simulations. CPY drift for all three watersheds was assumed to occur with all treated crops having a proximity to water equal to the minimum setback requirements on the product label. The setback was used to simulate drift reductions to water, but reductions in pesticide loadings in runoff were not assumed to occur in the setback area.

Opportunities to verify the focus-watershed model results were limited for this study. No calibration of runoff water, soil erosion, or CPY properties was conducted. However, it was possible to model several field-specific runoff studies (Cryer and Dixon-White 1995; McCall et al. 1984; Poletika and Robb 1994; Racke 1993) by using the environmental fate properties employed in the modeling of the focus watersheds. Predicted volumes of runoff water, sediment, and CPY concentrations in runoff water and in eroded sediment were within an order of magnitude of the amounts measured in runoff studies, and they were neither consistently high nor consistently low, suggestive of a lack of model prediction bias.

The analyses used to characterize runoff of CPY at the national level incorporated a number of generalizations. For this reason, these analyses were only used to evaluate the relative potential for runoff of CPY as a guide in selecting the focus watersheds. The most significant generalization was representing all simulations as a generic crop (corn) with a unit application rate. Applications were set to occur 
relative to the typical date of corn emergence across the USA. Only two application scenarios were predicted-broadcast sprays to soil and to foliage. Volatilization was not simulated in the foliar application scenario. Granular applications and cropspecific label-type applications were not evaluated. The scenarios used in the sensitivity analysis on use-patterns are another relative indicator of the runoff potential of CPY because they represent a hypothetical environment-a 10-ha field draining into a 1 -ha by $2-\mathrm{m}$ deep pond. The pond remains at a constant volume that receives pesticide loads from drift and runoff, but not the corresponding influx of water that would occur during a runoff event.

The Orestimba Creek watershed in California was predicted to have the greatest exposure concentrations and the longest duration of exposures of the three watersheds. This is caused in part because of the relatively higher intensity of CPY's use, and because of the relatively small dilution and flushing that exists in the headwater channels. The watershed is under a water quality management plan administered by the Westside San Joaquin River Watershed Coalition to alter practices contributing to water quality issues associated with agricultural chemicals (CURES 2013; SJVDA 2010). The practices needing to be altered include education and outreach on pesticide application technologies and managing irrigation and storm-water runoff that were not taken into account in the model.

Characterization of CPY in the environment could be enhanced by including additional detail in all three watershed systems. These include heterogeneity in cropping and soils in Georgia and Michigan; management plans being introduced into Orestimba Creek, and weather specific drift estimates and application field proximity to water drainage-ways.

\section{Summary}

Concentrations of CPY in surface waters are an integral determinant of risk to aquatic organisms. CPY has been measured in surface waters of the U.S. in several environmental monitoring programs and these data were evaluated to characterize concentrations, in relation to major areas of use and changes to the label since 2001, particularly the removal of domestic uses. Frequencies of detection and 95th centile concentrations of CPY decreased more than fivefold between 1992 and 2010. Detections in 1992-2001 ranged from 10.2 to 53\%, while 20022010 detections ranged from 7 to $11 \%$. The 95th centile concentrations ranged from 0.007 to $0.056 \mu \mathrm{g} \mathrm{L}^{-1}$ in $1992-2001$ and $0.006-0.008 \mu \mathrm{g} \mathrm{L}^{-1}$ in $2002-2010$. The greatest frequency of detections occurred in samples from undeveloped and agricultural land-use classes. Samples from urban and mixed land-use classes had the smallest frequency of detections and 95th centile concentrations, consistent with the cessation of most homeowner uses in 2001. The active metabolite of CPY, CPYO, was not detected frequently or in large concentrations. In 10,375 analyses from several sampling programs conducted between 1999 and 2012, only 25 detections $(0.24 \%$ of samples) of CPYO were reported and estimated concentrations were less than the LOQ. 
Although the monitoring data on CPY provide relevant insight in quantifying the range of concentrations in surface waters, few monitoring programs have sampled at a frequency sufficient to quantify the time-series pattern of exposure. Therefore, numerical simulations were used to characterize concentrations of CPY in water and sediment for three representative high exposure environments in the U.S. The fate of CPY in the environment is dependent on a number of dissipation and degradation processes. In terms of surface waters, fate in soils is a major driver of the potential for runoff into surface waters and results from a number of dissipation studies in the laboratory were characterized. Aerobic degradation of CPY exhibits bi-phasic behavior in some soils; initial rates of degradation are greater than overall rates by factors of up to threefold. Along with fate in water, these data were considered in selecting parameters for the modeling concentrations in surface waters. An assessment of vulnerability to runoff was conducted to characterize the potential for CPY to be transported beyond a treated field in runoff water and eroded sediment across the conterminous U.S. A sensitivity analysis was performed on use practices of CPY to determine conditions that resulted in the highest potential runoff of CPY to aquatic systems to narrow the application practices and geographical areas of the country for selecting watersheds for detailed modeling. The selected focus-watersheds were Dry Creek in Georgia (production of pecans), Cedar Creek in Michigan (cherries), and Orestimba Creek in California (intensive agricultural uses). These watersheds provided realistic but reasonable worst-case predictions of concentrations of CPY in water and sediment.

Estimated concentrations of CPY in water for the three watersheds were in general agreement with ambient monitoring data from 2002 to 2010 in the datasets from US Geological Survey (USGS), California Department of Pesticide Regulation (CDPR), and Washington State Department of Ecology (WDOE). Maximum daily concentrations predicted for the watershed in California, Georgia, and Michigan were $3.2,0.041$, and $0.073 \mu \mathrm{g} \mathrm{L}^{-1}$, respectively, with the 28 -d aerobic soil metabolism half-life and 4.5, 0.042, and $0.122 \mu \mathrm{g} \mathrm{L}^{-1}$, respectively, with the 96-d soil halflife. These estimated values compared favorably with maximum concentrations measured in surface water, which ranged from 0.33 to $3.96 \mu \mathrm{g} \mathrm{L}^{-1}$. For sediments, the maximum daily concentrations predicted for the watersheds in California, Georgia, and Michigan were 11.2, 0.077, and $0.058 \mu \mathrm{g} \mathrm{kg}^{-1}$, respectively, with the 28-d half-life and 22.8, 0.080, and $0.087 \mu \mathrm{g} \mathrm{kg}^{-1}$, respectively, with the 96-d soil half-life. CYP was detected in 12 samples (10\%) out of 123 sample analyses that existed in the USGS, CDPR, and WDOE databases. The concentrations reported in these detections were from $<2.0$, up to $19 \mu \mathrm{g} \mathrm{kg}^{-1}$, with the exception of one value reported at $58.6 \mu \mathrm{g} \mathrm{kg}^{-1}$. Again, the modeled values compared favorably with these measured values. Duration and recovery intervals between toxicity threshold concentrations of 0.1 and $1.0 \mu \mathrm{g} \mathrm{L}^{-1}$ were also computed. Based on modeling with the half-life of $28 \mathrm{~d}$, no exceedance events were identified in the focus watersheds in Georgia or Michigan. Using the half-life of $96 \mathrm{~d}$, only three events of 1-d duration only were identified in the Michigan focus-watershed. Frequency of exceedance was greater in the California focus watershed, though the median duration was only 1-d. 
Acknowledgments The authors thank Jeff Wirtz of Compliance Services International; and J. Mark Cheplick, Dean A. Desmarteau, Gerco Hoogeweg, William J. Northcott, and Kendall S. Price, all of Waterborne Environmental for their contributions to this paper. We also acknowledge Yuzhou Luo, previously with the University of California, for providing the SWAT dataset for the Orestimba Creek watershed. We thank the anonymous reviewers of this paper for their suggestions and constructive criticism. Prof. Giesy was supported by the Canada Research Chair program, a Visiting Distinguished Professorship in the Department of Biology and Chemistry and State Key Laboratory in Marine Pollution, City University of Hong Kong, the 2012 "High Level Foreign Experts" (\#GDW20123200120) program, funded by the State Administration of Foreign Experts Affairs, the P.R. China to Nanjing University and the Einstein Professor Program of the Chinese Academy of Sciences. Funding for this work was provided by Dow AgroSciences.

Open Access This chapter is distributed under the terms of the Creative Commons Attribution Noncommercial License, which permits any noncommercial use, distribution, and reproduction in any medium, provided the original author(s) and source are credited.

\section{References}

Banks KE, Hunter DH, Wachal DJ (2005) Chlorpyrifos in surface waters before and after a federally mandated ban. Environ Int 31:351-356

Batzer FR, Fontaine DD, White FH (1990) Aqueous photolysis of chlorpyrifos. DowElanco, Midland, MI, Unpublished Report

Budd R, O'Geen A, Goh KS, Bondarenko S, Gan J (2009) Efficacy of constructed wetlands in pesticide removal from tailwaters in the Central Valley, California. Environ Sci Technol 43: 2925-2930

Burns L (2004) Exposure analysis modeling system (EXAMS): user manual and system documentation. Version 2.98.04.06. Ecosystems Research Division U.S. Environmental Protection Agency, Athens, GA, EPA/600/R-00/081

Carousel RF, Imhoff JC, Hummel PR, Cheplick JM, Donigian AS, Jr, Suárez LA (2005) PRZM_3, A Model for Predicting Pesticide and Nitrogen Fate in the Crop Root and Unsaturated Soil Zones: Users Manual for Release 3.12.2. National Exposure Research Laboratory, Office of Research and Development, U.S. Environmental Protection Agency, Athens, GA

CDPR (2012a) Surface water database. California department of pesticide regulation. http://www. cdpr.ca.gov/docs/emon/surfwtr/surfcont.htm. Accessed 24 Feb 2012

CDPR (2012b) Pesticide use reporting data: user guide \& documentation. California department of pesticide regulation. California Pesticide Information Portal (CalPIP). http://calpip.cdpr. ca.gov/. Accessed $28 \mathrm{Feb} 2012$

CEPA (2011a) State water resources control board. Surface water ambient monitoring program. California Environmental Protection Agency. http://www.waterboards.ca.gov/water_issues/ programs/swamp/. Accessed Aug 2011

CEPA (2011b) Central valley regional water quality control board. Irrigated Lands Regulatory Program. California Environmental Protection Agency. http://www.swrcb.ca.gov/rwqcb5/ water_issues/irrigated_lands/index.shtml/. Accessed Aug 2011

Cornell University Cooperative Extension (2012a) Crop and Pest Management Guidelines: 2012 New York and Pennsylvania Pest Management Guidelines for Grapes. http://ipmguidelines. org/Grapes/. Accessed Sept 2012

Cornell University Cooperative Extension (2012b) Crop and Pest Management Guidelines: 2012 Cornell Pest Management Guidelines for Commercial Turfgrass. http://ipmguidelines.org/ Turfgrass/. Accessed Sept 2012

Cryer S, Dixon-White H (1995) A field runoff study of chlorpyrifos in southeast Iowa during the severe flooding of 1993. DowElanco, Indianapolis, IN, Unpublished Report 
CURES (2013) Best Management Practices-Handbook \& Information. Coalition for Urban/ Rural Environmental Stewardship. available from http://www.curesworks.org/coalitions.asp, Davis, CA, USA pp $>100$

de Vette HQM, Schoonmade JA (2001) A study on the route and rate of aerobic degradation of ${ }^{14} \mathrm{C}$-chlorpyrifos in four European soils. Dow AgroSciences, Indianapolis, IN, Unpublished Report

Domagalski JL, Munday C (2003) Evaluation of Diazinon and Chlorpyrifos Concentrations and Loads, and Other Pesticide Concentrations, at Selected Sites in the San Joaquin Valley, California, April to August, 2001. U.S. Geological Survey, Sacramento, CA. Water-Resources Investigations Report 03-4088

AgroSciences D (2009) Lorsban advanced insecticide supplemental labeling. Dow AgroSciences LLC, Indianapolis, IN

AgroSciences D (2010) Lorsban advanced insecticide label. Dow AgroSciences LLC, Indianapolis, IN

ECOFRAM (1999) ECOFRAM Aquatic Final Draft Reports. United States Environmental Protection Agency, Washington, DC. http://www.epa.gov/oppefed1/ecorisk/aquareport.pdf

Ensminger M, Bergin R, Spurlock F, Goh KS (2011) Pesticide concentrations in water and sediment and associated invertebrate toxicity in Del Puerto and Orestimba Creeks, California, 2007-2008. Environ Monit Assess 175:573-587

Fendinger NJ, Glotfelty DE (1990) Henry's law constants for selected pesticides, PAHs, and PCBs. Environ Toxicol Chem 9:731-736

FOCUS (2012) Overview of FOCUS. Forum for the Co-ordination of pesticide fate models and their Use. http://viso.ei.jrc.it/focus/. Accessed Nov 2012

Gesch DB (2007) The national elevation dataset digital elevation model technologies and applications: the DEM Users manual. In: Maune D (ed) Digital elevation model technologies and applications: the DEM Users manual, 2nd edn. American Society for Photogrammetry and Remote Sensing, Bethesda, MD, pp 99-118

Giddings JM, Williams WM, Solomon KR, Giesy JP (2014) Risks to aquatic organisms from the use of chlorpyrifos in the United States. Rev Environ Contam Toxicol 231:119-162

Gill SL, Spurlock FC, Goh KS, Ganapathy C (2008) Vegetated ditches as a management practice in irrigated alfalfa. Environ Monit Assess 144:261-267

Glotfelty DE, Seiber JN, Liljedahl LA (1987) Pesticides in fog. Nature Biotech 325:602-605

Gomez LE (2009) Use and benefits of chlorpyrifos in US agriculture. Dow AgroSciences, Indianapolis, IN, Unpublished Report

Hoogeweg CG, Williams WM, Breuer R, Denton D, Rook B, Watry C (2011) Spatial and Temporal Quantification of Pesticide Loadings to the Sacramento River, San Joaquin River, and BayDelta to Guide Risk Assessment for Sensitive Species. CALFED Science Grant \#1055. CALFED Science Program, Sacramento,CA.

Hoogeweg CG, Denton DL, Breuer R, Williams WM, TenBrook P (2012) Development of a spatial-temporal co-occurrence index to evaluate relative pesticide risks to threatened and endangered species. In: Racke KD, McGaughey BD, Cowles JL, Hall AT, Jackson SH, Jenkins JJ, Johnston JJ (eds) Pesticide regulation and the endangered species Act, vol 1111. American Chemical Society, Washington, DC, pp 303-323

Johnson HM, Domagalski JL, Saleh DK (2011) Trends in pesticide concentrations in streams of the western United States, 1993-2005. J Am Water Res Assoc 47:265-286

Jones RL, Russell MH (eds) (2001) FIFRA environmental model validation task force final report. American Crop Protection Association, Washington, DC. http://femvtf.com/femvtf/Files/ FEMVTFbody.pdf

Kennard LM (1996) Aerobic aquatic degradation of chlorpyrifos in a flow-through system. DowElanco, Indianapolis, IN, Unpublished Report

Long RF, Hanson BR, Fulton A (2010) Mitigation techniques reduce sediment in runoff from furrow-irrigated cropland. Calif Agric 64:135-140 
Luo Y, Zhang X, Liu X, Ficklin D, Zhang M (2008) Dynamic modeling of organophosphate pesticide load in surface water in the northern San Joaquin Valley watershed of California. Environ Pollut 156:1171-1181

Luo Y, Zhang M (2010) Spatially distributed pesticide exposure assessment in the Central Valley, California, USA. Environ Pollut 158:1629-1637

MacDougall D, Crummett WB (1980) Guidelines for data acquisition and data quality evaluation in environmental chemistry. Anal Chem 52:2242-2249

Mackay D, Giesy JP, Solomon KR (2014) Fate in the environment and long-range atmospheric transport of the organophosphorus insecticide, chlorpyrifos and its oxon. Rev Environ Contam Toxicol 231:35-76

Martin JD, Eberle M (2009) Adjustment of pesticide concentrations for temporal changes in analytical recovery, 1992-2010. U.S. Geological Survey, Reson, VA

Martin JD, Eberle M, Nakagaki N (2011) Sources and preparation of data for assessing trends in concentrations of pesticides in streams of the United States, 1992-2010. U.S. Geological Survey, Reson, VA

McCall PJ, Oliver GR, McKellar RL (1984) Modeling the runoff potential and behavior of chlorpyrifos in a terrestrial-aquatic watershed. Dow Chemical, Midland, MI, Unpublished Report

NASQAN (2012) USGS National Stream Quality Accounting Network. United States Geological Survey. http://water.usgs.gov/nasqan/. Accessed $24 \mathrm{Feb} 2012$

NAWQA (2012) USGS National Water Quality Assessment Data Warehouse. United States Geological Survey. http://infotrek.er.usgs.gov/apex/f?p=NAWQA:HOME:0. Accessed 24 Feb 2012

NCWQR (2012) Tributary Monitoring Program. National Center for Water Quality Research. http://www.heidelberg.edu/wql/tributarydatadownload. Accessed Feb 2013

Neitsch SL, Arnold JG, Kiniry JR, Srinivasan R, Williams JR (2010) Soil and water assessment tool theoretical documentation, version 2009.TR-265. Grassland, Soil and Water Research Laboratory, Agricultural Research Service, Temple, TX

Orang MN, Snyder RL, Matyar JC (2008) Survey of irrigation methods in California in 2001. J Irrig Drain Eng 134:96-100

Parker R, Arnold JG, Barrett M, Burns L, Carrubba L, Neitsch SL, Snyder NJ, Srinivasan R (2007) Evaluation of three watershed-scale pesticide environmental transport and fate models. J Am Water Res Assoc 43:1424-1443

Poletika NN, Robb CK (1994) A field runoff study of chlorpyrifos in Mississippi delta cotton. DowElanco, Indianapolis, IN, Unpublished Report

Racke KD (1993) Environmental fate of chlorpyrifos. Rev Environ Contam Toxicol 131:1-151

Racke KD, Juberg DR, Cleveland CB, Poletika NN, Loy CA, Selman FB, Bums CJ, Bartels MJ, Price PS, Shaw MC, Tiu CC (2011) Dow AgroSciences' Response to EPA's Preliminary Human Health Assessment for Chlorpyrifos Registration Review. Dow AgroSciences, Indianapolis, IN. EPA-HQ-OPP-2008-0850-0025. Report ID: KDR09062011

Reeves GL, Mackie JA (1993) The aerobic degradation of ${ }^{14} \mathrm{C}$-chlorpyrifos in natural waters and associated sediments. Dow Agrosciences, Indianapolis, IN, Unpublished Report

Rotondaro A, Havens PL (2012) Direct flux measurement of chlorpyrifos and chlorpyrifos-oxon emissions following applications of Lorsban advanced insecticide to alfalfa. Dow AgroScience, Indianapolis, IN, Unpublished Report

Ryberg KR, Vecchia AV, Martin JD, Gilliom RJ (2010) Trends in Pesticide Concentrations in Urban Streams in the United States, 1992-2008. U.S. Geological Survey, Reston, VA. U.S. Geological Survey Scientific Investigations Report 2010-5139

SJVDA (2010) Westside San Joaquin River Watershed Coalition. Focused Watershed Management Plan II. Westley Wasteway, Del Puerto Creek, Orestimba Creek. San Joaquin Valley Drainage Authority, available from http://www.waterboards.ca.gov/centralvalley/water_issues/irrigated_ lands/management_plans_reviews/coalitions/westside/index.shtml, Los Banos, CA, USA pp 16

Snyder NJ, Williams WM, Denton DL, Bongard CJ (2011) Modeling the effectiveness of mitigation measures on the Diazinon labels. In: Goh KS, Bret BL, Potter TL, Gan J (eds) Pesticide mitigation strategies for surface water quality. DC pp, American Chemical Society, Washington, pp $227-257$ 
Solomon KR, Williams WM, Mackay D, Purdy J, Giddings JM, Giesy JP (2014) Properties and uses of chlorpyrifos in the United States. Rev Environ Contam Toxicol 231:13-34

Starner K, Spurlock FC, Gill S, Feng H, Hsu J, Lee P, Tran D, White J (2005) Pesticide residues in surface water from irrigation-season monitoring in the San Joaquin Valley, California. Bull Environ Contam Toxicol 74:920-927

Sullivan DJ, Vecchia AV, Lorenz DL, Gilliom RJ, Martin JD (2009) Trends in Pesticide Concentrations in Corn-Belt Streams, 1996-2006. United States Geological Survey, Reston, VA. United States Geological Survey Scientific Investigations Report 2009-5132

Suntio LR, Shiu WY, Mackay D, Seiber JN, Glotfelty D (1987) A critical review of Henry's constants for pesticides. Rev Environ Contam Toxicol 103:1-59

Teske ME, Bird SL, Esterly DM, Ray SL, Perry SG (2002) A User's Guide for AgDRIFT ${ }^{\circledR} 2.0 .05$, Regulatory Version. CDI, Ewing, NJ. C.D.I. Report No. 01-02

USDA-ERS (2000) Farm Resource Regions. United States Department of Agriculture, Economic Research Service, Washington, DC. AIB-760 http://webarchives.cdlib.org/wayback.public/ UERS_ag_1/20111128195215/http://www.ers.usda.gov/Briefing/ARMS/resourceregions/ resourceregions.htm\#older

USDA (2012) National Agricultural Statistics Service. United States Department of Agriculture. http://www.nass.usda.gov/Surveys/Guide_to_NASS_Surveys/Chemical_Use/index.asp. Accessed April, Aug, Sept 2012

USDHHS (1997) Toxicological profile for chlorpyrifos. United States Department of Health and Human Services, Washington, DC, TP 84

USEPA (1999) Reregistration eligibility science chapter for chlorpyrifos: fate and environmental risk assessment chapter. United States Environmental Protection Agency, Washington, DC

USEPA (2000) Drinking Water Screening Level Assessment Part A: Guidance for Use of the Index Reservoir in Drinking Water Exposure Assessments. United States Environmental Protection Agency. Pesticide Science Policy. Office of Pesticide Programs, Washington DC. http://www. epa.gov/pesticides/trac/science/reservoir.pdf

USEPA (2006) EPA Reach File references. United States Environmental Protection Agency, Washington, DC. http://www.epa.gov/waters/doc/rfindex.html

USEPA (2009) Guidance for Selecting Input Parameters in Modeling the Environmental Fate and Transport of Pesticides: Version 2.1. United States Environmental Protection Agency, Office of Pesticide Programs, Environmental Fate and Effects Division, Washington, DC. http://www. epa.gov/oppefed1/models/water/

USEPA (2011) Revised Chlorpyrifos Preliminary Registration Review Drinking Water Assessment. United States Environmental Protection Agency, Office of Chemical Safety and Pollution Prevention, Washington, DC, USA. PC Code 059101 http://www.epa.gov/oppsrrd1/ registration_review/chlorpyrifos/EPA-HQ-OPP-2008-0850-DRAFT-0025\%5B1\%5D.pdf

USEPA (2012) Specified Ingredient Incidents for the Date Range 01/01/2002 to 06/15/2012. United States EPA Office of Pesticide Programs, Washington, DC

USGS (2013) NAWQA Database. United States Geological Survey. http://infotrek.er.usgs.gov/ servlet/page?_pageid=543\&_dad=portal30\&_schema=PORTAL30. Accessed 2 Feb 2013

WDOE (2012) Environmental Information Management Database. Washington State Department of Ecology. http://www.ecy.wa.gov/eim/. Accessed 3 April 2012

Weston D, Holmes R, You J, Lydy M (2005) Aquatic toxicity due to residential use of pyrethroid insecticides. Environ Sci Technol 39:9778-9784

Zhang X, Starner K, Spurlock F (2012) Analysis of chlorpyrifos agricultural use in regions of frequent surface water detections in California, USA. Bull Environ Contam Toxicol 89: 978-984 